\title{
Modeling Carbon Nanotube Connectivity and Surface Activity in a Contact Lens Biofuel Cell
}

Russell C. Reid ${ }^{[a]^{*}}$, Sean R. Jones ${ }^{[a]}$, David P. Hickey ${ }^{[b]}$, Shelley D. Minteer ${ }^{[b]}$, Bruce K. Gale $^{[\mathrm{a}]}$

${ }^{[a]}$ Department of Mechanical Engineering, University of Utah

${ }^{[b]}$ Department of Chemistry, University of Utah

1495 East 100 South, Salt Lake City, Utah 84112, United States

*E-mail: russ.reid@utah.edu

\section{Abstract}

Biofuel cells are often limited by the current density produced by the cathode; this is especially true when such fuel cells are scaled down to fit a desired application. Herein, we created a computational model to examine the effects of carbon nanotube (CNT) connectivity and surface activity on the current density of a biofuel cell cathode. The model was motivated by the creation of a novel contact lens biofuel cell that, although more stable and biocompatible than previously reported designs, was cathode limited. The device produced a maximum current density of $22 \pm 4 \mu \mathrm{Acm}^{-2}$, and a maximum power density of $2.4 \pm 0.9 \mu \mathrm{W} \mathrm{cm}$ (at $0.163 \mathrm{~V}$ ) with an open-circuit voltage of $0.44 \pm$ $0.08 \mathrm{~V}$. Computational results showed that in a Nafion film containing $1.6 \%$ CNTs by volume, less than $20 \%$ of the CNT fibers were connected to the electrode, assuming a planar electrode. The simulations predicted that a three-fold increase in CNT loading 
would lead to a roughly two-fold increase in total CNT connectivity. The simulations further estimated that for the CNTs connected to the electrode, only $21 \%$ of their sidewalls were contributing to cathodic current, meaning that the remaining surfaces were not electrochemically active. Given the low bilirubin oxidase (BOD) enzyme surface concentration, which was experimentally found to be $1.24 \times 10^{-13} \mathrm{~mol} \mathrm{~cm}^{-2}$, it is likely that large portions of the CNT surfaces are not connected to enzymes. This result validates the push by the research community to increase BOD and laccase adsorption/orientation to CNT surfaces.

\section{Keywords}

Biofuel cell; computational modeling; carbon nanotube matrix; contact lens

\section{Introduction}

Enzymatic biofuel cells convert chemical energy to electricity using enzymatic catalysts. With origins in living systems, enzymatic catalysts operate well in physiological temperature and $\mathrm{pH}$, which makes them an attractive option as a possible implantable power source [1-10]. Several examples of biofuel cells operating under such conditions have been reported, including some that operate in biological fluids [1115]. The trends in power output and stability for biofuel cells are clearly positive, but operational stability remains a significant limitation.

Enzymatic biofuel cells are generally less stable than their transition metal counterparts due largely to thermal degradation of the biological catalyst. Many attempts have been made to improve biofuel cell stability; however, existing biofuel cells 
are still shy of the 5-10 year lifetime of common implantable devices such as pacemakers and implantable cardioverter defibrillators (ICD) $[16,17]$. Meeting the stability requirements of fully implantable devices will continue to be a major goal for enzymatic biofuel cell research; however, an alternative approach involves the use of wearable biofuel cells that can be easily replaced on a regular basis. For example, wearable biofuel cells have recently been integrated into flexible textiles [18, 19], iontophoresis patches [20], temporary tattoos [21], and contact lenses [22, 23].

We recently reported a contact lens biofuel cell created using carbon paper comprised of carbon nanotubes (CNT), called buckypaper, electrodes modified with poly(methylene green), nicotinamide adenine dinucleotide $\left(\mathrm{NAD}^{+}\right)$, and lactate dehydrogenase (LDH) at the anode, and with anthracene-pyrene (An-pyr) and bilirubin oxidase (BOD) at the cathode [23]. However, the use of adsorbed $\mathrm{NAD}^{+}$as a cofactor results in inherent instability due to desorption of poly(methylene green) and adds significant complexity with respect to substrate and cofactor diffusion. As a potentially simpler alternative anode system, we recently reported [24] a high current density selfpowered lactate sensor that utilizes a flavin adenine dinucleotide (FAD)-dependent lactate oxidase (LOx) that was "wired" to an electrode surface using a dimethylferrocene-modified linear poly(ethylenimine) ( $\mathrm{FcMe}_{2}$-LPEI) redox polymer, where the redox polymer simultaneously immobilizes the enzyme at the electrode surface and facilitates rapid electron transfer between the enzyme's active site and electrode. While using this system produced a simpler, more stable anode, the cathode continued to be problematic, requiring a high enzyme and CNT loading as well as a larger projected surface area to match the anodic current. 
Enzymatic biofuel cells are commonly cathode-limited and this is currently an area of focused research [25]. The use of infused CNTs in an enzyme-immobilizing film is a highly effective method of increasing electrode surface area [26], yet only those CNTs that are electrically connected to the electrode surface contribute to electrocatalytic current. Additionally, only portions of the CNT surface may be electrochemically active [27-31]. Yet another important limitation is that not all the enzymes are able to communicate with or are "wired" to electrochemically active CNT sites. In a direct electron transfer (DET) system, limitations related to CNT connectivity, surface activity, and enzyme wiring are amplified compared to a mediated system, because the mediators increase the likelihood of electron transfer from enzymes to the current collector.

Analytical [32-35] and Numerical [36-44] modeling are useful, although arguably underutilized, tools for understanding enzymatic biofuel cell operational mechanisms. In an effort to better understand CNT-related limitations in enzymatic biofuel cell electrodes, especially those using DET, we built a series of prototypes and simulations that are reported herein. The first portion of this paper describes a contact lens biofuel cell prototype that was created as an experimental system to allow for computational analysis. It will be shown that cathode limitations were quite pronounced in the contact lens biofuel cell, so the second portion of this paper examines CNT-related factors contributing to low biocathode electrical current. CNT connectivity to the electrode was estimated using Monte Carlo simulation. The results were used in a COMSOL model to simulate current-potential data, which was fit to experimental data to estimate CNT electroactive/wired surface area. Although the modeling portion of this paper was 
performed with the contact lens biocathode specifically in mind, the results are applicable to any bioelectrode modified with a CNT-filled enzyme immobilizing polymer.

\section{Experimental}

\subsection{Lens and Electrode Fabrication}

A 3D-printed contact lens mold was created that had a concave, hand-polished, spherical surface, which defined contact lens curvature, and a sharp edge at the spherical surface's boundaries to control lens outer diameter. On the underside of the mold was a cylindrical protrusion used for centering the mold in a spin coater during lens curing. Fig. 1 shows CAD cross-sectional and isometric views of the mold, including important mold dimensions defining the contact lens features. The electrode

shapes were defined using a mask made from laser-cut vinyl tape (Gerber Instachange Removable Film). The mask was created in such a way so that the electrodes would have the correct size and shape and would be located around the perimeter of the lens once the mask was adhered to the cylindrical mold surface (Fig. 2).

Fig. 1

The carbon paste used for the electrodes was based on a formulation reported by Sameenoi et al. [45], but with an increased wt. percentage of polydimethylsiloxane (PDMS) for additional mechanical stability. The carbon paste was a mixture of $45 \%$ (by weight) $12-15 \mu \mathrm{m}$ graphite (Asbury Graphite, type 5601), 5\% multi-walled CNT (MWCNT) (outer diameter: Ø25 nm, length: $20 \mu \mathrm{m}$, Cheap Tubes, Inc.), 25\% mineral oil (Mallinckrodt \#6358), and 35\% polydimethylsiloxane (PDMS) (Sylgard 184, 10:1 w/w 
base:cross-linker). The graphite and MWCNT were thoroughly mixed in a small tube, the mineral oil and PDMS were added, and the paste was mixed with a small spatula until the consistency was visually uniform (approximately one minute of mixing). With the electrode mask adhered to the mold, the carbon paste was applied over the mask with the spatula. Removing the mask left patterned carbon paste electrodes on the mold surface where the contact lens would be formed. Transparent UV-curable silicone rubber (Shin-Etsu product X-34-4184) base and cross linker was mixed in a 10:1 w/w base:cross-linker ratio and 110-115 mg was poured into the mold over the carbon paste electrodes. The amount of elastomer was important for achieving the desired final contact lens thickness $(300-400 \mu \mathrm{m})$ and outer diameter $(\sim \varnothing 15 \mathrm{~mm})$. The mold was placed into a spin coater (Laurell, WS-400A-6NPP-LITE) with the lid up and spun at 400 rpm for 15-17 minutes while exposing it to a 100-Watt UV light source (Blak-Ray) placed roughly 3 inches from the mold. The cured lens was then carefully removed from the mold before the carbon paste was fully cured and placed in an oven at $60^{\circ} \mathrm{C}$ for an hour to cure the carbon paste electrodes. Removing the lens from the mold before the carbon paste fully cured was important, because it sheared the carbon paste, leaving part of the paste on the mold, while removing the paste that had cured to the lens. This increased the electrode surface approximately 60 times (Figure 4.2F) based on surface area measurements made using the electrochemically accessible surface area (EASA) method [46] and assuming a specific capacitance of $20 \mu \mathrm{F} \mathrm{cm}{ }^{-2}$. Small wires were attached to the electrodes using conductive silver epoxy (Electron Microscopy Sciences), which was then insulated with clear epoxy (5 Minute ${ }^{\circledR}$ Epoxy, Devcon). Not including electrode areas bonded to wire leads, the anode and cathode geometric 
surface areas were about $0.04 \mathrm{~cm}^{2}$ and $0.2 \mathrm{~cm}^{2}$, respectively. The cathode was larger in an attempt to overcome cathode limitations.

Fig. 2

\subsection{Contact Lens Electrode Enzyme Immobilization}

Fig. 3 schematically illustrates the enzymatic modifications made to the electrodes after the contact lens electrodes were fabricated. Anodic enzymes were immobilized in a previously reported dimethylferrocene-modified linear polyethyleneimine ( $\left.\mathrm{FcMe}_{2}-\mathrm{LPEI}\right)$ redox polymer [47] that has proven to be very effective at mediating electron transfer for oxidation of glucose [47], fructose [48], ethanol [49], and lactate [24]. Anode-modifying solutions containing $70.5 \% \mathrm{v} / \mathrm{v} \mathrm{FCME}{ }_{2}$-LPEl (10 $\mathrm{mg} \mathrm{ml}^{-1}$ in deionized water), $26 \% \mathrm{v} / \mathrm{v}$ LOx from Pediococcus sp. (200 U/ml, Sigma-Aldrich), and 3.5\% v/v ethylene glycol diglycidyl ether (EGDGE) $(2.5 \mu \mathrm{l}$ in $45 \mu \mathrm{l} \mathrm{DI}$ water, Polysciences, Inc.) were mixed thoroughly and $6 \mu \mathrm{l}$ was pipetted onto the anode and allowed to dry overnight at room temperature.

\section{Fig. 3}

On the cathode, a solution containing An-pyr modified CNT, BOD, and TBABmodified Nafion was pipetted and allowed to dry immediately before performing experiments. It was previously demonstrated that An-modified CNTs are capable of preferentially orienting BOD and laccase for improved DET cathodic current density [50, 51], which is why the previous contact lens biofuel cell buckypaper cathodes were thus modified. However, the CNT content of the carbon paste cathode in the current contact lens biofuel cell was insufficient for the paste to be directly modified with An-pyr, and 
attempts to add An-pyr CNT to the uncured carbon paste did not show DET (data not shown). This is why An-pyr CNT were placed on the carbon paste surface. The cathode solution consisted of $75 \% \mathrm{v} / \mathrm{v}$ BOD solution (12 $\mathrm{mg} \mathrm{ml}^{-1}$ in PBS, $\mathrm{pH} 7.4$ ) and $25 \% \mathrm{v} / \mathrm{v}$ TBAB-modified Nafion. The BOD was from Myrothecium sp. and was purchased from Amano and the TBAB-modified Nafion was prepared as described previously [52]. The enzyme/Nafion solution was mixed by vortexing and then An-pyr CNTs, prepared previously, were added to the solution resulting in a concentration of $8.3 \mathrm{mg} \mathrm{ml}^{-1} \mathrm{An}-\mathrm{pyr}$ CNTs, and the mixture was vortexed for $1 \mathrm{~min}$ and sonicated for $15 \mathrm{~s}$. After repeating the vortex/sonication process another 3 times, $30 \mu$ of this solution were pipetted onto the cathode, carefully spread over the electrode surface, and allowed to dry for 2 hours. Finally, the cathode was coated with silicone acrylate polymer (Nexcare Skin Crack Care) for improved biocompatibility. While this coating is not typically used for ocular implants or lenses, it was more flexible and adhered better than PMMA and polystyrene films. Cathodic current density was negatively impacted by these coatings, but whether the decrease in current was due to lower oxygen diffusivity or decreased enzymatic activity was not determined.

\subsection{Contact Lens Biofuel Cell Electrochemical Characterization}

The contact lens biofuel cell anode and cathode were first characterized separately in a three-electrode experimental setup and then together on the contact lens. For the three-electrode experiments, anodes and cathodes were created from flat elastomer samples cured to carbon paste with a geometric electrode area of $0.15 \mathrm{~cm} \times 0.45 \mathrm{~cm}$. The enzyme solution volume on the flat electrodes was adjusted to account for the 
aerial difference compared to the contact lens electrodes. These flat electrode samples were used as the working electrodes in separate anode and cathode experiments while a platinum mesh and a saturated calomel electrode (SCE) were, respectively, used as the counter and reference electrodes. All anode, cathode, and biofuel cell experiments were performed in an artificial tear solution consisting of $0.05 \mathrm{mM} \beta$-D-glucose, $3 \mathrm{mM} \mathrm{L-}$

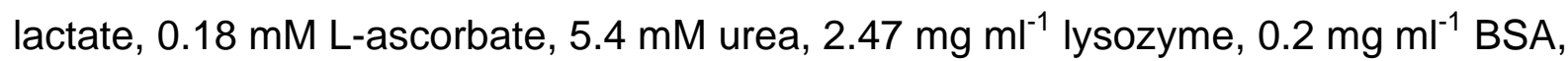
and $0.15 \mathrm{mg} \mathrm{ml}^{-1}$ mucin, all in $150 \mathrm{mM}$ PBS with the final $\mathrm{pH}$ adjusted to 7.4. The tear solution was placed in a beaker and was maintained at eye surface temperature, $35^{\circ} \mathrm{C}$ [53], using a refrigerated/heated bath circulator (Isotemp 4100, Fisher Scientific). For the contact lens biofuel cell experiments, tear solution was dripped onto the lens every five seconds using a syringe pump (Pump 11 Elite, Harvard Apparatus). The droplet temperature was controlled using a flexible Kapton heater (Omegalux) which was wrapped around the tubing near its outlet, while the heater and a thermocouple (Omega) were connected to a temperature controller (Omegaette CN4216). Rather than using a test stand, as was used for our previous contact lens biofuel cell prototype, the newer prototype was tested in vitro. The prototype's wire leads were bent at a right angle so that the contact lens could be maintained in a horizontal position while being immersed enough for the electrodes to be fully wetted with tear solution, which was simpler than using the test stand and still kept the electrodes close to the solution surface. Electrochemical measurements were made using a Digi-Ivy DY2300 potentiostat. Contact lens biofuel cells were tested by performing linear polarization beginning at the open circuit voltage (OCV) and ending at the closed circuit voltage, 0 $\mathrm{V}$, at a scan rate of $1 \mathrm{mV} \mathrm{s}^{-1}$ while measuring the output current. Power curves were 
created by multiplying the measured current and the corresponding applied voltage. Current and power densities were calculated based on electrode geometric surface area. For the biofuel cell, the cathode area $\left(0.2 \mathrm{~cm}^{2}\right)$ was used because it was the larger of the two electrodes, while for the separated anode/cathode three-electrode experiments the electrode area was $0.0675 \mathrm{~cm}^{2}$. Unless otherwise specified, experiments were performed in triplicate and reported uncertainty corresponds to one standard deviation.

\subsection{CNT Connectivity Simulation}

A Monte Carlo MATLAB simulation was created to examine CNT networking in the contact lens biofuel cell cathode. The simulation was based on a previously published percolation study for randomly oriented bent CNT fibers [54]. Various Monte Carlo percolation studies have been performed beginning with the work of Pike and Seager [55]; the goal generally being to determine the carbon volume percentage required to guarantee a conductive pathway through an insulating binder. The simulation in the present research focuses instead on determining the true electrode surface area and how CNT content and film thickness might contribute to cathode current density.

Rather than recreate a CNT matrix on a roughened carbon paste electrode surface (as was used for the contact lens biofuel cell), the model simulated a CNT film on a flat surface such as a glassy carbon (GC) electrode. Not only did this simplify the model, it also decoupled CNT networking from the effect that varied surface morphology may have on connectivity, making the results more generally applicable while still revealing characteristics of the contact lens CNT network. Important model parameters designed 
to mimic those from experiments included the CNT-filled TBAB-modified Nafion thickness, which was measured using a Tencor P-10 profilometer and a Fisher Micromaster light microscope. The film was pipetted onto a flat substrate and the dry thickness was measured using the profilometer to determine a baseline value. After hydrating the film in phosphate buffer for four hours, the thickness was measured using the light microscope connected to a desktop computer. Having calibrated the microscope camera's measurement software, thickness measurements were taken with the film oriented so its thickness was perpendicular to the microscope view. The resulting measurements were by no means precise, but were sufficiently accurate for the rough model contained in this paper. The volume percentage of CNT, $\phi_{C}$, in the film determined the number of CNTs in the simulation and was calculated from the known mass of CNT placed on the electrode, the CNT density from the supplier's datasheet $\left(2.1 \mathrm{~g} \mathrm{~cm}^{3}\right)$, and the measured hydrated film thickness. The CNT supplier's datasheet was also the source of CNT average outside diameter $(25 \mathrm{~nm})$ and length $(20 \mu \mathrm{m})$-two other important model parameters. All CNTs in the model were assumed to have the same dimensions and were assumed to be uniformly distributed within a film of constant thickness.

The MATLAB code followed the previously published percolation study by Ma and Gao [54], basically creating a network of randomly placed CNTs and then determining if any of them were close enough to form a cluster. The clusters were then evaluated for contact with the electrode at $z=0$. The model assumed an electron hopping distance $d_{e}=1.8 \mathrm{~nm}[56]$ to determine if CNTs that are not physically touching were electrically 
connected. The key equation in the CNT connectivity model defined the minimum distance between any two CNT fibers as:

$$
d_{\min }=\left(\frac{C_{2}^{2} C_{4}+C_{1}^{2}+C_{3}^{2}-C_{1} C_{2} C_{3}-4 C_{4}}{C_{2}^{2}-4}\right)^{1 / 2}
$$

where

$$
\begin{gathered}
C_{1}=2 \Delta x \cos \theta_{m}^{i} \sin \alpha_{m}^{i}+2 \Delta y \sin \theta_{m}^{i} \sin \alpha_{m}^{i}+2 \Delta z \cos \alpha_{m}^{i} \\
C_{2}=-2\left[\sin \alpha_{m}^{i} \sin \alpha_{n}^{j} \cos \left(\theta_{m}^{i}-\theta_{n}^{j}\right)+\cos \alpha_{m}^{i} \cos \alpha_{n}^{j}\right] \\
C_{3}=-2 \Delta x \cos \theta_{n}^{j} \sin \alpha_{n}^{j}-2 \Delta y \sin \theta_{n}^{j} \sin \alpha_{n}^{j}-2 \Delta z \cos \alpha_{n}^{j} \\
C_{4}=(\Delta x)^{2}+(\Delta y)^{2}+(\Delta z)^{2}
\end{gathered}
$$

and

$$
\Delta x=x_{i}-x_{j}, \quad \Delta y=y_{i}-y_{j}, \quad \Delta z=z_{i}-z_{j},
$$

In Eqs. (1-3, the subscripts $i$ and $j$ refer to the $i^{\text {th }}$ and $j^{\text {th }}$ fibers and $x, y$, and $z$ are the fiber vertex coordinates in three-dimensional space. The fibers have a vertex because they were modeled as bent fibers consisting of two branches of the same length with a random angle from $0^{\circ}$ to $180^{\circ}$ between them. Modeling the CNT as bent fibers was an attempt to compromise between the reality of long, inter-tangled CNT fibers, and an oversimplified scenario consisting of CNTs modeled as straight fibers. The other variables in Eq. 2 are the orientation angles for each fiber arm (see Ma and Gao [54]) with $m, n=1,2$ because each fiber has two arms. Two CNTs were connected if the minimum distance between them, defined by Eq. (1, was less than or equal to the CNT diameter plus $d_{e}$. 


\subsection{Cathodic Current Density Simulation}

Cathodic current density was simulated using a steady state 2D-axisymmetric COMSOL model of a single BOD-coated CNT in a TBAB-modified Nafion film. The CNT was situated coaxially to the model axis and the CNT midpoint was located $111 \mu \mathrm{m}$ from the film surface because that was the location of the average CNT networked to the electrode, as determined using the MATLAB connectivity model. Rather than model active sites on the CNT surface, the simulation CNT length varied depending on the electrochemically active CNT surface fraction, which was the parameter used to fit experimental and simulated values. Fig. 4 shows the CNT oriented in the film.

Fig. 4

The oxygen concentration at the film surface was maintained at the concentration of dissolved oxygen in water while an oxygen-consuming flux was placed on the CNT surface. All other boundaries were made electrically and physically insulating. The model was repeated with an oxygen gradient (due to BOD-catalyzed $\mathrm{O}_{2}$ reduction in a biocathode film) applied to the right boundary instead of a constant oxygen concentration at the top boundary. The effect on the model results was minimal. Current density was calculated by integrating the flux over the CNT surface, then multiplying by the number of CNTs in the film and the fraction of CNTs connected to the electrode (from the MATLAB simulation). Finally, as shown in Eq. 6, this quantity was divided by the GC surface area to obtain the cathodic current density.

The oxygen flux equation at the carbon nanotube surface (Eq. 4) assumed a twostep electron transfer process between the CNT and oxygen (Fig. 4). Electron transfer from the CNT to BOD was described using a simplified Butler-Volmer expression, while 
electron transfer from BOD to oxygen was defined using the Michaelis Menten equation. Eq. 4 is the equation for oxygen flux, $J_{O_{2}}$ at the CNT surface [39]:

$$
D_{O_{2}}\left(\frac{\partial\left[O_{2}\right]}{\partial \vec{n}}\right)_{C N T}=\frac{1}{\frac{1}{\Gamma_{e} k_{f}\left[O_{2}\right]}+\frac{\left[O_{2}\right]+K_{\mathrm{M}}}{\Gamma_{e} k_{c a t}\left[O_{2}\right]}}=J_{O_{2}}
$$

where the forward reaction rate constant, $k_{f}$, is defined in Butler-Volmer form as [57]:

$$
k_{f}=k_{0} \exp \left[-\alpha F\left(E-E_{0}\right)\right]
$$

In Eqs. 4 and 5, $D_{\mathrm{O}_{2}}$ is the oxygen diffusion coefficient through TBAB-modified Nafion, $\left[\mathrm{O}_{2}\right]$ is the concentration of dissolved oxygen in solution, $\Gamma_{e}$ is the BOD surface concentration on the CNT, $K_{\mathrm{M}}$ is the Michaelis constant, $k_{\text {cat }}$ is the turnover number, $k_{0}$ is the heterogeneous rate constant, $\alpha$ is the cathodic transfer coefficient, $F$ is Faraday's constant, $E$ is the applied potential from $0.6 \mathrm{~V}$ to $0.0 \mathrm{~V}$, and $E_{0}$ is the oxygen reduction onset potential. After the COMSOL model solved for the oxygen flux at the CNT surface, the cathodic current density was calculated as follows:

$$
j=\frac{n_{e, \mathrm{O}_{2}} F n_{C N T} f_{\text {conn }} \int_{C N T} J_{O_{2}} d A}{A_{G C}}
$$

where $n_{e, \mathrm{O}_{2}}=4$ is the number of electrons transferred in the reduction of oxygen to water [46], $n_{C N T}$ is the number of CNTs in the entire electrode film, $f_{\text {conn }}$ is the fraction of CNTs connected to the electrode, and $A_{G C}$ is the GC electrode surface area $(0.0707$ $\mathrm{cm}^{2}$ ). The surface integral was computed by COMSOL over the revolved CNT surface.

Experimentally determined model parameters included $\alpha, E_{0}, \Gamma_{e}$ and $K_{\mathrm{M}}$ while other model parameters were acquired from literature sources. Experimentally determined parameters were obtained using polished GC electrodes with an An-pyrMWCNT/TBAB-modified Nafion/BOD film similar to the film used on the contact lens 
biofuel cell except the concentration of BOD was increased to saturation. The BOD concentration was saturated to approximate a situation where all CNT active sites are in communication with the enzyme, which was one of the COMSOL model assumptions. All experimentally determined parameters were obtained from experiments performed in quiescent $50 \mathrm{mM}$ phosphate buffer adjusted to $\mathrm{pH} 7.4$ and using an SCE reference electrode and platinum mesh counter electrode.

$E_{0}$ was determined by visual examination of a cyclic voltammogram with applied potentials ranging from 0.6 to $0.0 \mathrm{~V}$ and a scan rate of $2 \mathrm{mV} \mathrm{s}^{-1} . \alpha$ was obtained from the non-transport affected region of the same cyclic voltammogram, using the recently proposed method given by the IUPAC [58]. To find $\Gamma_{e}$, cyclic voltammograms were generated in $\mathrm{N}_{2}$-purged solution and the biocatalytic charge transfer was calculated by integrating the area under the oxidation peak, which occurred at an approximate potential of $0.46 \mathrm{~V}$ (and taking into account the scan rate). The charge was used in Eq. 7 to yield $\Gamma_{e}$ as follows:

$$
\Gamma_{e}=\frac{Q}{n_{e, \mathrm{BOD}} F A}
$$

where $Q$ is the charge, $n_{e, \mathrm{BOD}}=1$ is the number of electrons involved in BOD oxidation, and $A$ is the total CNT surface area that is networked to the electrode and is based on the MATLAB connectivity model data. $K_{\mathrm{M}}$ was determined from the measured cathodic current at various concentrations of dissolved oxygen while applying $0.25 \mathrm{~V}$ (vs. SCE). Electrodes were initially immersed in an $\mathrm{N}_{2}$-purged solution to establish a baseline and the oxygen concentration was measured using an oxygen probe (Accumet, AP84) while injections were made from an $\mathrm{O}_{2}$-saturated solution. A curve based on the MichaelisMenten equation was fit to the resulting data to obtain $K_{\mathrm{M}}$. 
The model simulated cathodic current density at seven applied potentials ranging from 0.0 to $0.6 \mathrm{~V}$ vs. SCE. The electrochemically active CNT surface area fraction, $f_{\text {active }}$, was modified in order to fit the simulated current density to experimental data. The experimental data was obtained by measuring the stable cathodic current produced at each potential using the same electrodes and buffer as were used for measuring the experimentally determined model parameters. Table 1 summarizes the parameters used in the CNT connectivity model and the cathode current density model.

\section{Table 1}

\section{Results and Discussion}

\subsection{Contact Lens Biofuel Cell}

Half-cell experimental results for the anode and cathode are shown in Fig. 5. Cyclic voltammograms of the anode (Fig. 5A) show a typical reversible dimethylferrocene redox couple with an oxidation peak at $0.25 \mathrm{~V}$ vs. SCE and an enzyme-catalyzed lactate oxidation onset potential at $-0.025 \mathrm{~V}$ vs. SCE. These results are consistent with those recently reported in a self-powered, $\mathrm{FcME}_{2}$-LPEI-mediated lactate sensor [24]. The

maximum catalytic current density, $j_{\max }$, for the anode was $825 \pm 58 \mu \mathrm{A} \mathrm{cm}^{-2}$ (at $70 \mathrm{mM}$ lactate). This large electrochemical response to lactate can be attributed to both the efficient wiring of LOx to the electrode surface by $\mathrm{FcMe}_{2}$-LPEI and to high surface roughness on the contact lens electrodes. The inset of Fig. 5A shows the amperometric response of the bioanode at a lactate concentration of $3 \mathrm{mM}$, which is the lactate concentration in tears. The resulting $j_{\text {max }}$ is $133 \pm 13 \mu \mathrm{A} \mathrm{cm}^{-2}$. Fig. 5B displays the 
cathode cyclic voltammograms with an onset potential for oxygen reduction at $0.48 \mathrm{~V}$ vs. SCE and a cathodic $j_{\max }$ of $34 \pm 8 \mu \mathrm{A} \mathrm{cm}{ }^{-2}$. Catalytic current for both electrodes was higher in the half-cell experiments than in the full biofuel cell experiment, because the half-cell samples did not require epoxied leads and a biocompatibility coating was not used on the cathode. The mismatch between values of $j_{\max }$ for the anode and cathode determined how much larger the cathode was made in relation to the anode. Stability data, shown in Fig. 5C, was collected only for the anode, because it was the primary source of low stability in our previously reported contact lens biofuel cell prototype [23]. That earlier prototype maintained only $7 \%$ of its initial current after 17 hours of continuous testing. Fig. 5C highlights a markedly increased stability for the anode, maintaining $48 \%$ of current after 17 hours. The increased stability of the LOx / $\mathrm{FcMe}_{2}-$ C3-LPEI redox system used here is somewhat unsurprising given that in a previously reported glucose biosensor utilizing a similar mediating polymer, ca. $75 \%$ of the electrode's initial current was produced after 17 hours of continuous testing [59].

\section{Fig. 5}

\section{Fig. 6}

Fig. 6 contains the contact lens biofuel cell power and polarization curves. Key characteristics are an OCV of $0.44 \pm 0.08 \mathrm{~V}$, a maximum current density of $22 \pm 4 \mu \mathrm{A}$ $\mathrm{cm}^{-2}$, and a maximum power density of $2.4 \pm 0.9 \mu \mathrm{W} \mathrm{cm}-2(0.5 \mu \mathrm{W})$ at $0.16 \mathrm{~V}$. For comparison, the OCV and maximum current and power densities for our previously reported contact lens biofuel cell were, respectively, $0.41 \pm 0.06 \mathrm{~V}, 61 \pm 3 \mu \mathrm{A} \mathrm{cm}{ }^{-2}$, and $8.0 \pm 1 \mu \mathrm{W} \mathrm{cm}{ }^{-2}$. The newer prototype therefore exhibited a slight increase in OCV, but significantly lower current and power densities, although a direct comparison between 
the two prototypes is not possible due to a much lower total surface area of the carbon paste electrodes compared to buckypaper. Using the EASA method with a general carbon material specific capacitance of $20 \mu \mathrm{F} \mathrm{cm}^{-2}$, the actual area of the newer contact lens biofuel cell cathode is roughly $63 \mathrm{~cm}^{2}$, which is $75 \%$ less than the previous cathode.

Another reason for the decreased current and power of the second prototype was the increased resistance from epoxied leads whereas the original prototype's connections were integral to the buckypaper electrodes. Additionally, the decreased enzyme activity and/or oxygen transport through the silicone acrylate biocompatibility coating for preventing CNT flaking off the cathode likely decreased substrate diffusion or restricted conformational freedom necessary to maintain enzyme activity. The decreases in current and power densities for the newer prototype were somewhat offset by improved biocompatibility and stability. The improved electrode lens adhesion and absence of buckypaper electrodes consisting almost entirely of CNT, which are not biocompatible [60], qualitatively make the newer contact lens biofuel more capable of being worn on the eye than our previous prototype.

\subsection{CNT Connectivity Simulation}

Electron transfer between an enzyme and a CNT within a biocathode film requires that the CNT be electrically connected to the electrode, either directly or through a network of interconnected CNTs. The CNT connectivity model was created to reveal the fraction of CNTs within the biocathode film that were connected to the electrode. Similar information is obtainable using electrochemical methods (using cyclic voltammetry to 
find EASA), which were previously used to estimate the surface area of the contact lens biofuel cell, but creating a model of individual fibers also provided additional information, such as the level of connectivity at various distances from the electrode. Nevertheless, measuring the EASA of the An-pyr-MWCNT/TBAB-modified Nafion/BOD film on GC electrodes provided a verification of the connectivity model's total surface area prediction. Whereas the connectivity model predicted $A=6.58 \mathrm{~cm}^{2}$, the EASA was measured to be $11.61 \mathrm{~cm}^{2}$. Similarly, using unmodified MWCNTs with a smaller diameter $(D=15 \mathrm{~nm}$ rather than $D=25 \mathrm{~nm}$ for the An-pyr-MWCNTs), the model predicted $A=18.91 \mathrm{~cm}^{2}$ and EASA was measured to be $23.66 \mathrm{~cm}^{2}$. A possible explanation for why EASA was higher than $A$ from the connectivity model is that EASA was calculated using a general value for carbon material specific capacitance that does not account for CNT length or diameter-two parameters that have a large impact on connectivity.

The first step in the simulation was to determine the minimum required sample volume so that connectivity results were independent of volume. Once the sample volume had a side length longer than the length of a CNT branch $(10 \mu \mathrm{m})$, the connectivity stabilized (see Fig. 7A). A minimum side length of $13 \mu \mathrm{m}$ was used for further simulations. It should be noted that although the data in Figure 7A models CNT connectivity from 0 to $0.5 \mu \mathrm{m}$ away from the electrode, a similar convergence was seen for other distances from the electrode. Fig. 7B and 7C show that CNT clusters of varying size form within the film.

Fig. 7 
The CNT/TBAB-modified Nafion film was measured to be $41.7 \pm 27 \mu$ m thick when dry and $125 \pm 50 \mu \mathrm{m}$ when hydrated, which is the measurement applicable to experiments performed in solution. To simulate CNT connectivity over the entire hydrated film thickness, the sample side lengths in the directions planar to the GC electrode were maintained at $13 \mu \mathrm{m}$ while the height of the sample cube was increased to $125 \mu \mathrm{m}$. CNT connectivity in the $125 \mu$ m-thick film can be seen in Fig. 8. Simulation results for four levels of CNT volume percentage, $\phi_{C}$, are shown in the figure, but the discussion here focuses around the results obtained for $\phi_{C}=1.6 \%$ because that is the value used on the contact lens biofuel cell cathode. The resulting connectivity curves have a half-Gaussian shape and reveal that connectivity immediately near the electrode is high, $89.7 \%$, but it drops off immediately, especially once the distance from the electrode exceeds the length of a CNT branch $(10 \mu \mathrm{m})$. Beyond the length of a CNT branch, the percent connectivity decreases at approximately a constant rate until, at ca. $40 \mu \mathrm{m}$ from the electrode, it levels off and at $65 \mu \mathrm{m}$ from the electrode, the connectivity is only $1 \%$. The percentage of CNT connected to the electrode in the entire film was $19.9 \pm 1 \%$.

Fig. 8

The connectivity model results may be useful to the many enzymatic biofuel cells that utilize CNT-filled polymer films for immobilizing enzymes. It was previously reported that the percolation threshold for a CNT matrix containing fibers with a length:diameter ratio of ca. 1000 would be approximately $\phi_{C}=0.1 \%$ [54]. Although all of the simulation results shown in Fig. 8 were obtained using $\phi_{C}>0.1 \%$, and although there is likely at least one conducting path through the film, the data reveal that connectivity 
improvements are possible by increasing $\phi_{C}$. For example, it was mentioned that for $\phi_{C}=1.6 \%$ at $65 \mu \mathrm{m}$ from the electrode, less than $1 \%$ of CNTs were connected to the electrode; if $\phi_{C}=4.5 \%$, connectivity at $65 \mu \mathrm{m}$ increases to $21 \%$. Chirkov and Rostokin used computer modeling to show that continuing to increase carbon content in an enzymatic film could ultimately allow complete electron penetration [61]. It should be kept in mind, however, that increasing $\phi_{C}$ may decrease oxygen diffusion through the film, although this was not explored for this paper. The model results also indicate that care should be taken when increasing film thickness, e.g. using a layer-by-layer enzyme immobilization process $[62,63]$. Although a thicker film will increase the amount of enzyme on the electrode, it may not improve current density if the film thickness exceeds the distance of probable CNT connectivity.

\subsection{Cathodic Current}

The experimentally determined model parameters were obtained using the data plotted in Fig. 9. The cyclic voltammogram in Fig. 9A was used to obtain $E_{0}$ and $\alpha$ while the cyclic voltammogram in Fig. 9B was used to calculate $\Gamma_{e}$. In Fig. 9B, the inset shows the background-subtracted oxidation peak at the location of the arrow in the main cyclic voltammogram of that portion of the figure. It was previously shown that the redox potential of the T1 copper site within the BOD is $0.43 \mathrm{~V}$ vs. SCE [64]. The T1 site is known to be responsible for electron transfer from the electrode to the enzyme; therefore, $\Gamma_{e}$ was calculated after integrating the area bound by this peak and the red line (which is the background current baseline) shown in the inset of Fig. 9B. From the known mass of CNTs and BOD in the film the theoretical maximum enzyme surface 
concentration was estimated to be $9.36 \times 10^{-12} \mathrm{~mol} \mathrm{~cm}^{-2}$. Considering that the measured $\Gamma_{e}=4.95 \times 10^{-13} \mathrm{~mol} \mathrm{~cm}^{-2}$, apparently only $5.3 \%$ of the enzyme in the film is wired to active CNT surfaces. This is slightly higher than percentages previously reported for other multi-copper oxidase (e.g. BOD and laccase) DET systems, which were 1-2\% [65, $66]$, but it is a lower surface concentration than the $5.0 \times 10^{-12} \mathrm{~mol} \mathrm{~cm}^{-2}$ that was recently reported by Lalaoui et al. [67] who utilized porphyrin molecules adsorbed to CNTs through $\pi-\pi$ interactions in order to accomplish BOD DET. The value for $K_{\mathrm{M}}$ from Fig. $9 \mathrm{C}$ is similar to what has previously been reported for BOD undergoing DET [68]. Finally, Fig. 9D contains the data used to determine the BOD saturation concentration that was used on all experimental electrodes used in conjunction with the COMSOL model. The saturation concentration reported is the concentration in the pipetted solution, not the cured and then hydrated film.

\section{Fig. 9}

Using the experimentally determined and literature parameters from Table1, the COMSOL model solved for cathodic current density from 0.6 to $0.0 \mathrm{~V}$ vs. SCE. $f_{\text {active }}$ was used as a free parameter to fit the simulated current potential data to experimental data, and the results can be seen in Fig. 10.

The fit between experimental and simulated data in Fig. 10 was achieved using $f_{\text {active }}=0.055$, which means that $5.5 \%$ of the CNT surface fulfilled both criteria of being electrochemically active and wired to BOD. Because a saturated enzyme concentration was used for the experiments, we can conclude that the $5.5 \%$ refers to the fraction of CNT sidewalls that are electrochemically active, which is a different result than what some researchers have found. Some studies show that the majority of CNT sidewalls 
are electrochemically active $[69,70]$. Even if only portions of the CNT sidewalls are electrochemically active [31], the $\Gamma_{e}$ obtained in this study shows that a denser enzyme packing is possible on the CNT surface. Recent work $[50,71,72]$ shows that improving enzyme adsorption to CNTs is possible. It was mentioned previously that, using porphyrins, $\Gamma_{e}$ was reportedly increased up to $5.0 \times 10^{-12}$ [67] which may be very close to the upper limit for $\Gamma_{e}$. Assuming a BOD diameter similar to laccase $(6.5 \mathrm{~nm})$ [73], and a closely packed enzyme monolayer, the maximum $\Gamma_{e}$ is $5.0 \times 10^{-12}$.

Fig. 10

\section{Conclusions}

CNT connectivity and CNT surface activity are two sometimes overlooked factors that impact DET electrode current density. The contact lens biofuel cell discussed herein was created as an experimental basis for computational CNT connectivity and surface activity models. The models were meant to provide insights into how to improve the biofuel cell contact lens cathode, but the results have application in any CNTmodified enzymatic biofuel cell or biosensor. The connectivity model revealed that increasing $\phi_{C}$ would have a positive impact on current output, assuming oxygen diffusion was not drastically impacted. The model also showed that increasing film thickness would likely not improve current output. Measuring enzyme surface concentration, $\Gamma_{e}$, revealed that the contact lens cathode system would benefit from a method for more densely adsorbing BOD to CNTs. In addition, the model estimated that the majority of CNT sidewalls were not electrochemically active. Finding methods to increase sidewall activity and $\Gamma_{e}$ would lead to dramatic increases in DET electrode 
current density, leading to large performance gains for the many biofuel cells and biosensors being developed.

The contact lens biofuel cell prototype presented herein was more suitable for oneye wearing than a previously reported prototype [23]. The carbon paste electrodes used in this work were very flexible, could stretch, and bonded well to silicone elastomer. The fabrication process used to combine the carbon paste electrodes with the contact lens demonstrated that these electrodes could be molded into many silicone-based devices. In addition to their flexibility, the electrodes were conductive enough and had a high enough surface area to be useful in a wearable biofuel cell or biosensor. Another possible application for the contact lens biofuel cell anode system is as a contact lens lactate sensor with higher sensitivity than has been previously demonstrated [74]. If the anode were combined with an improved cathode, a selfpowered wearable lactate sensor could be produced, which would be a novel contribution to the field of wearable lactate sensors.

\section{Acknowledgements}

The authors thank Dr. Fabien Giroud at the University of Grenoble for supplying the An-pyr-MWCNTs. This work was made possible through National Science Foundation (NSF) grant number 1057597.

\section{$\underline{\text { 5. References }}$}

[1] N. Mano, F. Mao, A. Heller, Characteristics of a Miniature Compartment-less Glucose-O2 Biofuel Cell and Its Operation in a Living Plant, J. Am. Chem. Soc. 125 (2003) 6588. 
[2] P. Cinquin, C. Gondran, F. Giroud, S. Mazabrard, A. Pellissier, F. Boucher, J. Alcaraz, K. Gorgy, F. Lenouvel, S. Mathe', P. Porcu, S. Cosnier, A Glucose BioFuel Cell Implanted in Rats, PLoS One 5 (2010) e10476.

[3] A. Zebda, S. Cosnier, J.P. Alcaraz, M. Holzinger, A. Le Goff, C. Gondran, F. Boucher, F. Giroud, K. Gorgy, H. Lamraoui, P. Cinquin, Single Glucose Biofuel Cells Implanted in Rats Power Electronic Devices, Sci. Rep. 3 (2013) 1516.

[4] S. Cosnier, A. Le Goff, M. Holzinger, Towards glucose biofuel cells implanted in human body for powering artificial organs: Review, Electrochem. Comm. 38 (2014) 19.

[5] T. Miyake, K. Haneda, N. Nagai, Y. Yatagawa, H. Onami, S. Yoshino, T. Abe, M. Nishizawa, Enzymatic biofuel cells designed for direct power generation from biofluids in living organisms, Energy \& Environmental Science 4 (2011) 5008-5012.

[6] L. Halamkova, J. Halamek, V. Bocharova, A. Szczupak, L. Alfonta, E. Katz, Implanted Biofuel Cell Operating in a Living Snail, Journal of the American Chemical Society 134 (2012) 5040-5043.

[7] A. Szczupak, J. Halamek, L. Halamkova, V. Bocharova, L. Alfonta, E. Katz, Living battery - biofuel cells operating in vivo in clams, Energy \& Environmental Science 5 (2012) 8891-8895.

[8] K. MacVittie, J. Halamek, L. Halamkova, M. Southcott, W.D. Jemison, R. Lobel, E. Katz, From "cyborg" lobsters to a pacemaker powered by implantable biofuel cells, Energy \& Environmental Science 6 (2013) 81-86.

[9] E. Katz, K. MacVittie, Implanted biofuel cells operating in vivo - methods, applications and perspectives - feature article, Energy \& Environmental Science 6 (2013) 2791-2803.

[10] E. Katz, Implantable Biofuel Cells Operating In Vivo-Potential Power Sources for Bioelectronic Devices, Bioelectronic Medicine 2 (2015) 1-12.

[11] Y. Holade, K. MacVittie, T. Conlon, N. Guz, K. Servat, T.W. Napporn, Boniface K, Katz E, Pacemaker Activated by an Abiotic Biofuel Cell Operated in Human Serum Solution, Electroanalysis 26 (2014) 2445.

[12] P. Lamberg, S. Shleev, R. Ludwig, T. Arnebrant, T. Ruzgas, Performance of enzymatic fuel cell in cell culture, Biosens. Bioelectron. 55 (2014) 168.

[13] A. Dector, R.A. Escalona-Villalpando, D. Dector, V. Vallejo-Becerra, A.U. Chávez-Ramírez, L.G. Arriaga, J. Ledesma-García, Perspective use of direct human blood as an energy source in air-breathing hybrid microfluidic fuel cells, J. Power Sources 288 (2015) 70.

[14] M. Falk, D. Pankratov, L. Lindh, T. Arnebrant, S. Shleev, Miniature Direct Electron Transfer Based Enzymatic Fuel Cell Operating in Human Sweat and Saliva, Fuel Cells 14 (2014) 1050.

[15] J.H, Lee, W.Y. Jeon, H.H. Kim, E.J. Lee, H.W. Kim, Electrical stimulation by enzymatic biofuel cell to promote proliferation, migration and differentiation of muscle precursor cells, Biomaterials 53 (2015) 358.

[16] V.S. Mallela, V. Ilankumaran, N. Rao, Trends in Cardiac Pacemaker Batteries, Indian Pacing, Electrophysiol. J. 4 (2004) 201. 
[17] F.W. Horlbeck, F. Mellert, J. Kreuz, G. Nickenig, J.O. Schwab, Real-World Data on the Lifespan of Implantable Cardioverter-Defibrillators Depending on Manufacturers and the Amount of Ventricular Pacing, J. Cardiovasc. Electrophysiol. 23 (2012) 1336.

[18] W. Jia, X. Wang, S. Imani, A.J. Bandodkar, J. Ramirez, P.P. Mercier, J. Wang, Wearable textile biofuel cells for powering electronics, J. Mater. Chem. A 2 (2014) 18184.

[19] Y. Ogawa, Y. Takai, Y. Kato, H. Kai, T. Miyake, M. Nishizawa, Stretchable biofuel cell with enzyme-modified conductive textiles, Biosens. Bioelectron. 74 (2015) 947.

[20] Y. Ogawa, K. Kato, T. Miyake, K. Nagamine, T. Ofuji, S. Yoshino, M. Nishizawa, Organic Transdermal Iontophoresis Patch with Built-in Biofuel Cell, Adv. Healthc. Mater. 4 (2015) 506.

[21] W. Jia, G. Valdes-Ramirez, A.J. Bandodkar, J.R. Windmiller, J. Wang, Epidermal biofuel cells: energy harvesting from human perspiration, Angew. Chem., Int. Ed. Engl. 52 (2013) 7233.

[22] M. Falk, V. Andoralov, Z. Blum, J. Sotres, D.B. Suyatin, T. Ruzgas, T. Arnebrant, S. Shleev, Biofuel cell as a power source for electronic contact lenses, Biosens. Bioelectron. 37 (2012) 38.

[23] R.C. Reid, S.D. Minteer, B.K. Gale, Contact lens biofuel cell tested in a synthetic tear solution, Biosens. Bioelectron. 68 (2015) 142.

[24] D.P. Hickey, R.C. Reid, R.D. Milton, S.D. Minteer, A self-powered amperometric lactate biosensor based on lactate oxidase immobilized in dimethylferrocene-modified LPEI, Biosens. Bioelectron. 77 (2016) 26.

[25] A. Le Goff, M. Holzinger, S. Cosnier, Recent progress in oxygen-reducing laccase biocathodes for enzymatic biofuel cells, Cell. Mol. Life Sci. 72 (2015) 941.

[26] S. Cosnier, M. Holzinger, A. Le Goff, Recent Advances in Carbon NanotubeBased Enzymatic Fuel Cells, Frontiers Bioeng. Biotechnol. 2 (2014) 45.

[27] C.E. Banks, R.R. Moore, T.J. Davies, R.G. Compton, Investigation of modified basal plane pyrolytic graphite electrodes: definitive evidence for the electrocatalytic properties of the ends of carbon nanotubes, Chem. Comm. (2004) 1804.

[28] A.F. Holloway, K. Toghill, G.G. Wildgoose, R.G. Compton, M.A.H. Ward, G. Tobias, S.A. Llewellyn, B. Ballesteros, M.L.H. Green, A. Crossley, Electrochemical Opening of Single-Walled Carbon Nanotubes Filled with Metal Halides and with Closed Ends, J. Phys. Chem. C 112 (2008) 10389.

[29] C.E. Banks, T.J. Davies, G.G. Wildgoose, R.G. Compton, Electrocatalysis at graphite and carbon nanotube modified electrodes: edge-plane sites and tube ends are the reactive sites, Chem. Comm. (2005) 829.

[30] C.E. Banks, A. Crossley, C. Salter, S.J. Wilkins, Compton RG. Carbon Nanotubes Contain Metal Impurities Which Are Responsible for the "Electrocatalysis" Seen at Some Nanotube-Modified Electrodes, Angew. Chem., Int. Ed. Engl. 45 (2006) 2533. 
[31] M.E. Snowden, M.A. Edwards, N.C. Rudd, J.V. Macpherson, P.R. Unwin, Intrinsic electrochemical activity of single walled carbon nanotube-Nafion assemblies, Phys. Chem. Chem. Phys. 15 (2013) 5030.

[32] P.N. Bartlett, K.F.E. Pratt, Theoretical treatment of diffusion and kinetics in amperometric immobilized enzyme electrodes Part I: Redox mediator entrapped within the film, Journal of Electroanalytical Chemistry 397 (1995) 61-78.

[33] T.A. Wey, M. Southcott, W.D. Jemison, K. MacVittie, E. Katz, Electrical Circuit Model and Dynamic Analysis of Implantable Enzymatic Biofuel Cells Operating In Vivo, Proceedings of the IEEE 102 (2014) 1795-1810.

[34] K. Saravanakumar, S.P. Ganesan, L. Rajendran, Theoretical Analysis of Reaction and Diffusion Processes in a Biofuel Cell Electrode, Fuel Cells 15 (2015) 523-536.

[35] M. Rasi, L. Rajendran, M.V. Sangaranarayanan, Enzyme-Catalyzed Oxygen Reduction Reaction in Biofuel Cells: Analytical Expressions for Chronoamperometric Current Densities, Journal of The Electrochemical Society 162 (2015) H671-H680.

[36] S. Calabrese Barton, Oxygen transport in composite mediated biocathodes, Electrochimica Acta 50 (2005) 2145-2153.

[37] T. Tamaki, T. Ito, T. Yamaguchi, Modelling of Reaction and Diffusion Processes in a High-surface-area Biofuel Cell Electrode Made of Redox Polymer-grafted Carbon, Fuel Cells 9 (2009) 37-43.

[38] P. Kar, W. Hao, H. Li, S.D. Minteer, S.C. Barton, Simulation of Multistep Enzyme-catalyzed Methanol Oxidation in Biofuel Cells, Journal of the Electrochemical Society 158 (2011) 580-6.

[39] J. Urban, A. Zloczewska, W. Stryczniewicz, M. Jönsson-Niedziolka, Enzymatic oxygen reduction under quiescent conditions - the importance of convection, Electrochemistry Communications 34 (2013) 94-97.

[40] R.C. Reid, F. Giroud, S.D. Minteer, B.K. Gale, Enzymatic Biofuel Cell with a Flow-through Toray Paper Bioanode for Improved Fuel Utilization, Journal of the Electrochemical Society 160 (2013) H612-H619.

[41] M.H. Osman, A.A. Shah, R.G.A. Wills, Detailed Mathematical Model of an Enzymatic Fuel Cell, Journal of The Electrochemical Society 160 (2013) F806F814.

[42] T.Q.N. Do, M. Varničić, R. Hanke-Rauschenbach, T. Vidaković-Koch, K. Sundmacher, Mathematical Modeling of a Porous Enzymatic Electrode with Direct Electron Transfer Mechanism, Electrochimica Acta 137 (2014) 616-626.

[43] Y. Song, V. Penmatsa, C. Wang, Modeling and Simulation of Enzymatic Biofuel Cells with Three-Dimensional Microelectrodes, Energies 7 (2014).

[44] T.Q.N. Do, M. Varničić, R.J. Flassig, T. Vidaković-Koch, K. Sundmacher, Dynamic and steady state 1-D model of mediated electron transfer in a porous enzymatic electrode, Bioelectrochemistry 106, Part A (2015) 3-13.

[45] Y. Sameenoi, M.M. Mensack, K. Boonsong, R. Ewing, W. Dungchai, O. Chailapakul, D.M. Cropek, C.S. Henry, Poly(dimethylsiloxane) cross-linked 
carbon paste electrodes for microfluidic electrochemical sensing, Analyst 136 (2011) 3177.

[46] S. Brocato, C. Lau, P. Atanassov, Mechanistic study of direct electron transfer in bilirubin oxidase, Electrochim. Acta 61 (2012) 44.

[47] M.T. Meredith, D.Y. Kao, D.P. Hickey, D.W. Schmidtke, D.T. Glatzhofer, High Current Density Ferrocene-Modified Linear Poly(ethylenimine) Bioanodes and Their Use in Biofuel Cells, J. Electrochem. Soc. 158 (2011) B166.

[48] F. Giroud, D.P. Hickey, D.W. Schmidtke, D.T. Glatzhofer, S.D. Minteer, A Monosaccharide-Based Coin-Cell Biobattery, ChemElectroChem 1 (2014) 1880.

[49] S. Aquino Neto, D.P. Hickey, R.D. Milton, A.R. De Andrade, S.D. Minteer, High current density $\mathrm{PQQ}$-dependent alcohol and aldehyde dehydrogenase bioanodes, Biosens. Bioelectron. 72 (2015) 247.

[50] F. Giroud, S.D. Minteer, Anthracene-modified pyrenes immobilized on carbon nanotubes for direct electroreduction of $\mathrm{O} 2$ by laccase, Electrochem. Comm. 34 (2013) 157.

[51] R.D. Milton, F. Giroud, A.E. Thumser, S.D. Minteer, R.C.T. Slade, Bilirubin oxidase bioelectrocatalytic cathodes: the impact of hydrogen peroxide, Chemical Communications 50 (2014) 94-96.

[52] B.L. Treu, S.D. Minteer, Isolation and purification of PQQ-dependent lactate dehydrogenase from Gluconobacter and use for direct electron transfer at carbon and gold electrodes, Bioelectrochem. 74 (2008) 73.

[53] M. Azharuddin, S.K. Bera, H. Datta, A.K. Dasgupta, Thermal fluctuation based study of aqueous deficient dry eyes by non-invasive thermal imaging, Exp. Eye Res. 120 (2014) 97.

[54] H.M. Ma, X.L. Gao, A three-dimensional Monte Carlo model for electrically conductive polymer matrix composites filled with curved fibers, Polymer 49 (2008) 4230.

[55] G.E. Pike, C.H. Seager, Percolation and conductivity: A computer study, I. Phys. Rev. B 10 (1974) 1421.

[56] C. Feng, L. Jiang, Micromechanics modeling of the electrical conductivity of carbon nanotube (CNT)-polymer nanocomposites, Composites, Part A 47 (2013) 143.

[57] A.J. Bard, L.R. Faulkner, Electrochemical Methods: Fundamentals and Applications, 2nd ed: John Wiley \& Sons, Inc., New York, 2001.

[58] R. Guidelli, R.G. Compton, J.M. Feliu, E. Gileadi, J. Lipkowski, W. Schmickler, S. Trasatti, Defining the transfer coefficient in electrochemistry: An assessment (IUPAC Technical Report), Pure Appl. Chem. 86 (2014) 245.

[59] S.A. Merchant, M.T. Meredith, T.O. Tran, D.B. Brunski, M.B. Johnson, D.T. Glatzhofer, D.W. Schmidtke, Effect of Mediator Spacing on Electrochemical and Enzymatic Response of Ferrocene Redox Polymers, J. Phy. Chem. C 114 (2010) 11627.

[60] M. Bottini, S. Bruckner, K. Nika, N. Bottini, S. Bellucci, A. Magrini, A. Bergamaschi, T. Mustelin, Multi-walled carbon nanotubes induce T lymphocyte apoptosis, Toxicol. Lett. 160 (2006) 121. 
[61] Y.G. Chirkov, V.I. Rostokin, Porous Electrodes with Immobilized Enzymes: The Fractal-Percolation Properties of Supports Manufactured from Particles of Finely Divided Colloidal Graphite, Russ. J. Electrochem. 41 (2005) 838.

[62] K.H. Hyun, S.W. Han, W.G. Koh, Y. Kwon, Fabrication of biofuel cell containing enzyme catalyst immobilized by layer-by-layer method, J. Power Sources 286 (2015) 197.

[63] R. Cui, H. Huang, Z. Yin, D. Gao, J.J. Zhu, Horseradish peroxidasefunctionalized gold nanoparticle label for amplified immunoanalysis based on gold nanoparticles/carbon nanotubes hybrids modified biosensor, Biosens. Bioelectron. 23 (2008) 1666.

[64] A. Christenson, S. Shleev, N. Mano, A. Heller, L. Gorton, Redox potentials of the blue copper sites of bilirubin oxidases, Biochim. Biophys. Acta, Bioenerg. 1757 (2006) 1634.

[65] D. Ivnitski, K. Artyushkova, P. Atanassov, Surface characterization and direct electrochemistry of redox copper centers of bilirubin oxidase from fungi Myrothecium verrucaria, Bioelectrochemistry 74 (2008) 101.

[66] M.T. Meredith, M. Minson, D.P. Hickey, K. Artyushkova, D.T. Glatzhofer, S.D. Minteer, Anthracene-Modified Multi-Walled Carbon Nanotubes as Direct Electron Transfer Scaffolds for Enzymatic Oxygen Reduction, ACS Catal. 1 (2011) 1683.

[67] N. Lalaoui, A. Le Goff, M. Holzinger, S. Cosnier, Fully Oriented Bilirubin Oxidase on Porphyrin-Functionalized Carbon Nanotube Electrodes for Electrocatalytic Oxygen Reduction, Chem. - Eur. J. 21 (2015) 16868.

[68] L. dos Santos, V. Climent, C.F. Blanford, F.A. Armstrong, Mechanistic studies of the 'blue' Cu enzyme, bilirubin oxidase, as a highly efficient electrocatalyst for the oxygen reduction reaction, Phys. Chem. Chem. Phys. 12 (2010) 13962.

[69] I. Heller, J. Kong, H.A. Heering, K.A. Williams, S.G. Lemay, C. Dekker, Individual Single-Walled Carbon Nanotubes as Nanoelectrodes for Electrochemistry, Nano Lett. 5 (2005) 137.

[70] A.G. Güell, N. Ebejer, M.E. Snowden, K. McKelvey, J.V. Macpherson, P.R. Unwin, Quantitative nanoscale visualization of heterogeneous electron transfer rates in 2D carbon nanotube networks, Proc. Natl. Acad. Sci. 109 (2012) 11487.

[71] R.J. Lopez, S. Babanova, Y. Ulyanova, S. Singhal, P. Atanassov, Improved Interfacial Electron Transfer in Modified Bilirubin Oxidase Biocathodes, ChemElectroChem 1 (2014) 241.

[72] Y. Ulyanova, S. Babanova, E. Pinchon, I. Matanovic, S. Singhal, P. Atanassov, Effect of enzymatic orientation through the use of syringaldazine molecules on multiple multi-copper oxidase enzymes, Phys. Chem. Chem. Phys. 16 (2014) 13367.

[73] S. Shleev, J. Tkac, A. Christenson, T. Ruzgas, A.I. Yaropolov, J.W. Whittaker, L. Gorton, Direct electron transfer between copper-containing proteins and electrodes, Biosens. Bioelectron. 20 (2005) 2517.

[74] N. Thomas, I. Lahdesmaki, B.A. Parviz, A contact lens with an integrated lactate sensor, Sens. Actuators, B 162 (2012) 128. 
[75] V.A. Sethuraman, S. Khan, J.S. Jur, A.T. Haug, J.W. Weidner, Measuring oxygen, carbon monoxide and hydrogen sulfide diffusion coefficient and solubility in Nafion membranes, Electrochim. Acta 54 (2009) 6850.

[76] G.A. Truesdale, A.L. Downing, Solubility of Oxygen in Water, Nature 173 (1954) 1236.

[77] J. Lim, N. Cirigliano, J. Wang, B. Dunn, Direct electron transfer in nanostructured sol-gel electrodes containing bilirubin oxidase, Physical Chemistry Chemical Physics 9 (2007) 1809-1814.

[78] P. Agbo, J.R. Heath, H.B. Gray, Modeling Dioxygen Reduction at Multicopper Oxidase Cathodes, Journal of the American Chemical Society 136 (2014) 1388213887. 


\section{Figure Captions}

Fig. 1. CAD model of the contact lens mold showing dimensions that defined the contact lens; on the left is a cross-sectional view and on the right is a 3D isometric view.

Fig. 2. Contact lens biofuel cell fabrication steps. (A) A laser-cut electrode tape mask is placed in the mold, (B) carbon paste is applied over the mask, (C) the mask is removed revealing the patterned carbon paste electrodes, and (D) UV-curable elastomer is poured over the electrodes and cured while the mold is spinning to produce the lens with electrodes molded into them; $(E)$ shows the finished device with leads attached to it; $(F)$ carbon paste electrode surface area increased when the carbon paste was transferred to the lens material before the paste fully cured.

Fig. 3. Contact lens biofuel cell schematic showing the immobilized enzymes and mediator.

Fig. 4. COMSOL cathode current density model geometry with a reaction schematic for electron transfer from the CNT to oxygen through BOD.

Fig. 5. Contact lens biofuel cell anode and cathode experimental data. (A) Anode halfcell cyclic voltammograms in tear solution: without lactate (solid line), with $70 \mathrm{mM}$ lactate (dash-dot line), and a control (no LOx, $70 \mathrm{mM}$ lactate, dotted line). The inset shows current vs. lactate concentration at an applied voltage of 0.3 V. (B) Cathode halfcell cyclic voltammograms in air-saturated (solid line) and $\mathrm{N}_{2}$-purged (dashed line) tear solution. (A) and (B) performed using a scan rate $=1 \mathrm{mV} \mathrm{s}^{-1}$, SCE reference electrode. (C) Anode stability with an applied potential of $0.35 \mathrm{~V}$ at $35^{\circ} \mathrm{C}$ in $3 \mathrm{mM}$ lactate.

Fig. 6. Contact lens biofuel cell polarization (left axis) and power curves (right axis) scanned at $1 \mathrm{mV} \mathrm{s}^{-1}$

Fig. 7. (A) Convergence graph showing the minimum volume side length and corresponding number of CNTs (in thousands) to obtain a stable CNT connectivity percentage. (B) and (C): MATLAB images of CNT clusters containing just a few fibers (B) and many fibers (C); the $z$-axis is not to scale.

Fig. 8. (A) Percentage CNTs connected to the electrode in a 125- $\mu \mathrm{m}$ thick film for various vol. \% CNT fill, $\phi_{\mathrm{C}}: 0.25 \%(\bigcirc) ; 1.6 \%(\bullet) ; 3 \%(\triangle) ; 4.5 \%(\mathbf{\Delta})$. (B) MATLAB image displaying only those CNTs connected to the electrode, shown as black lines. 
Fig. 9. Experimental data collected to obtain model parameters. An-pyr-MWCNT/TBABmodified Nafion/BOD on GC in 50 mM phosphate, $\mathrm{pH} 7.4$, SCE reference electrode used for all experiments. (A) Cyclic voltammetry in air-saturated (solid line) and $\mathrm{N}_{2}$ saturated (dashed line) solutions at a scan rate of $2 \mathrm{mV} \mathrm{s}^{-1}$ used to obtain $E_{0}$ and $\alpha_{\text {. }}$ (B) Cyclic voltammogram in $\mathrm{N}_{2}$-saturated solution saturation at a scan rate of $10 \mathrm{mV} \mathrm{s}^{-1}$ used to calculate $\Gamma_{e}$. (C) Amperometric data at $0.25 \mathrm{~V}(\mathrm{n}=1)$ used to obtain $K_{M}$, the red line is the Michaelis Menten curve fit. (D) Amperometric data at $0.1 \mathrm{~V}(\mathrm{n}=1)$ used to determine the saturation value for BOD concentration.

Fig. 10. Experimental (black squares) and simulated (red triangles) cathode current density at various potentials. 
$\mathrm{R} 8.5 \mathrm{~mm}$
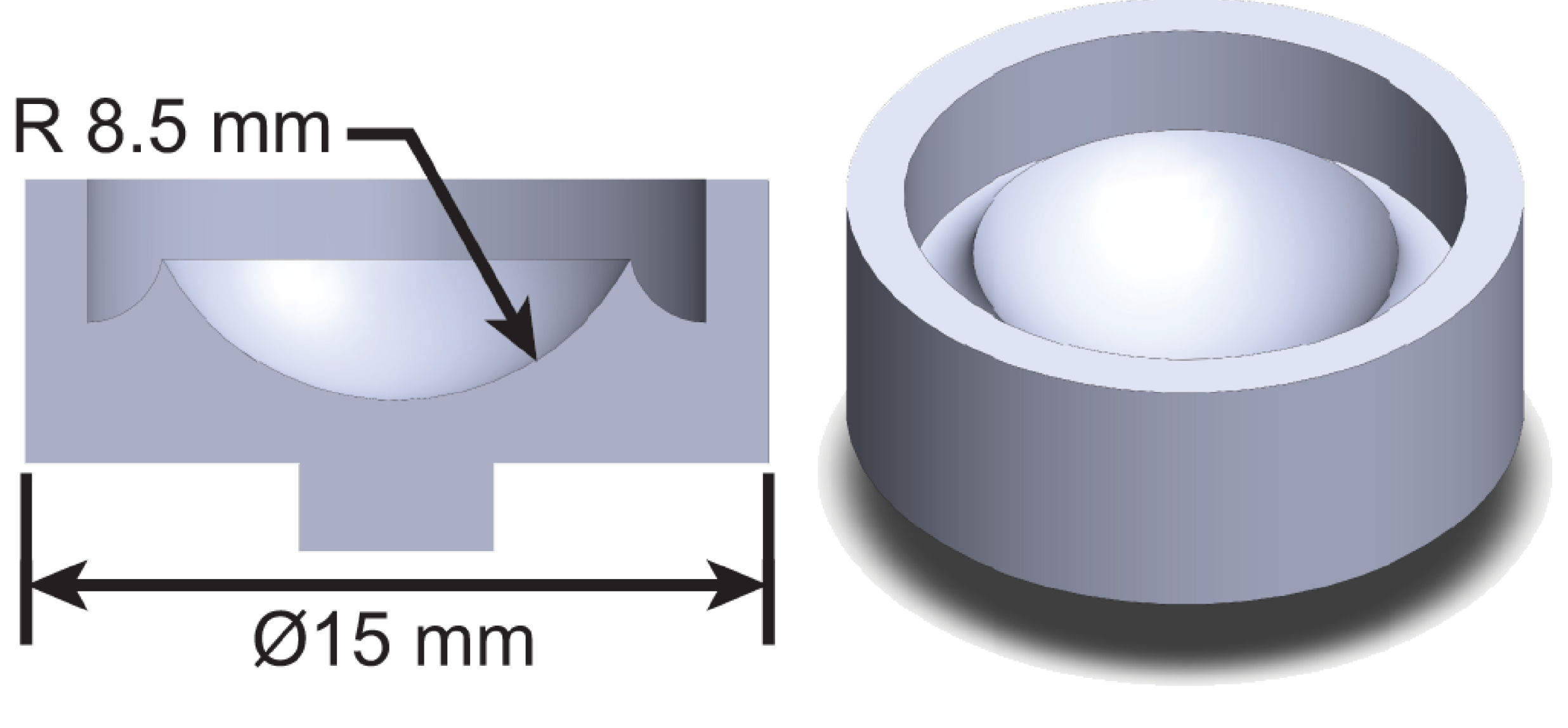


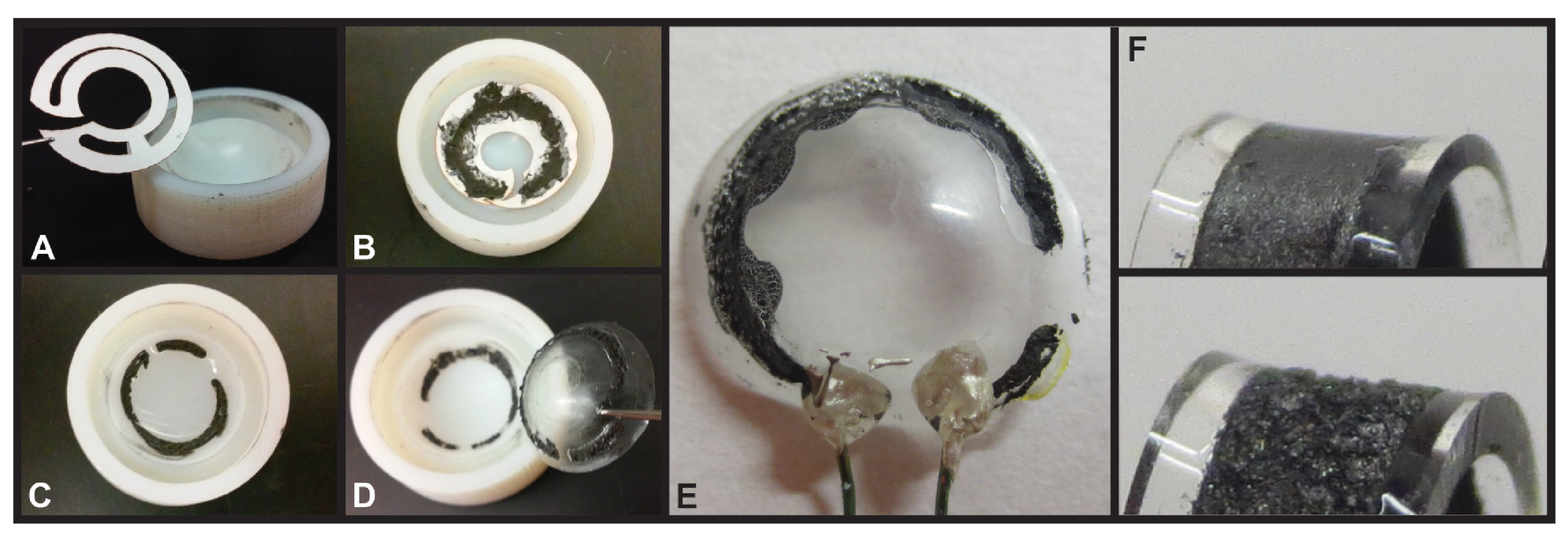

Figure 2 


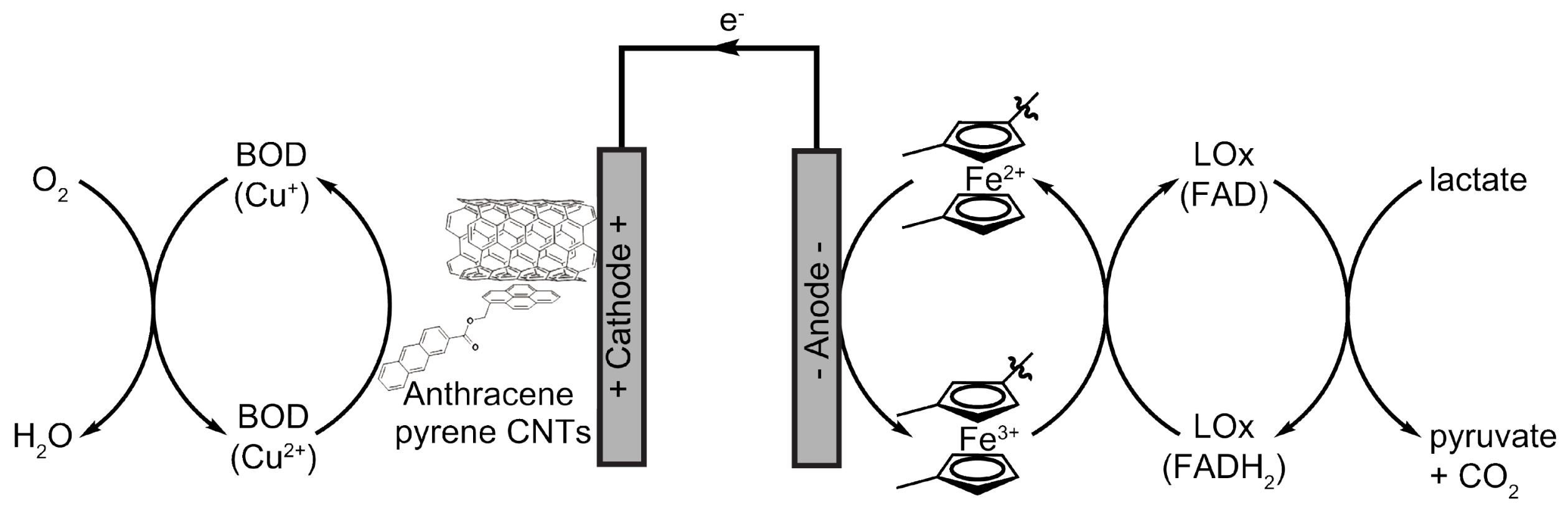




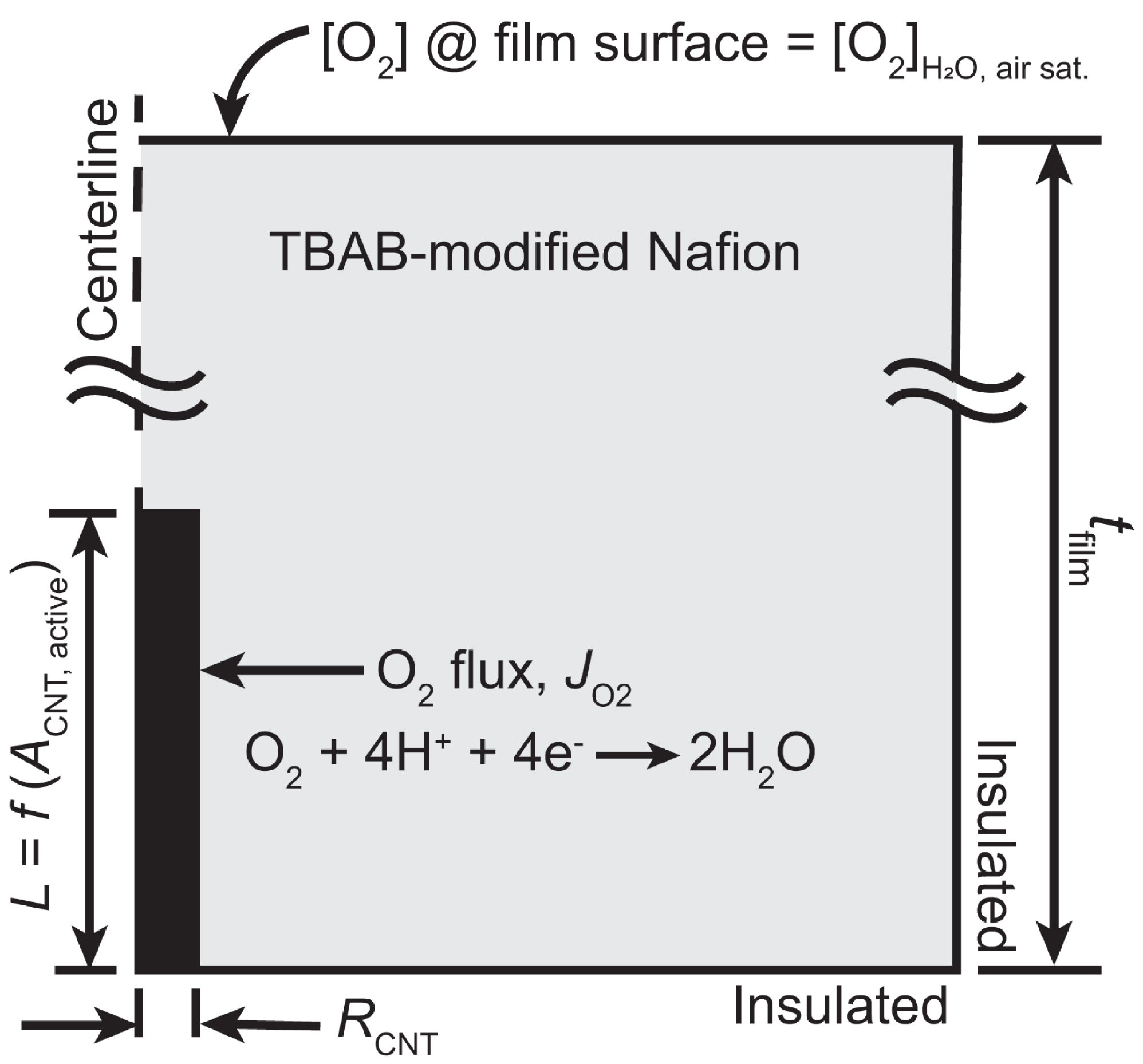



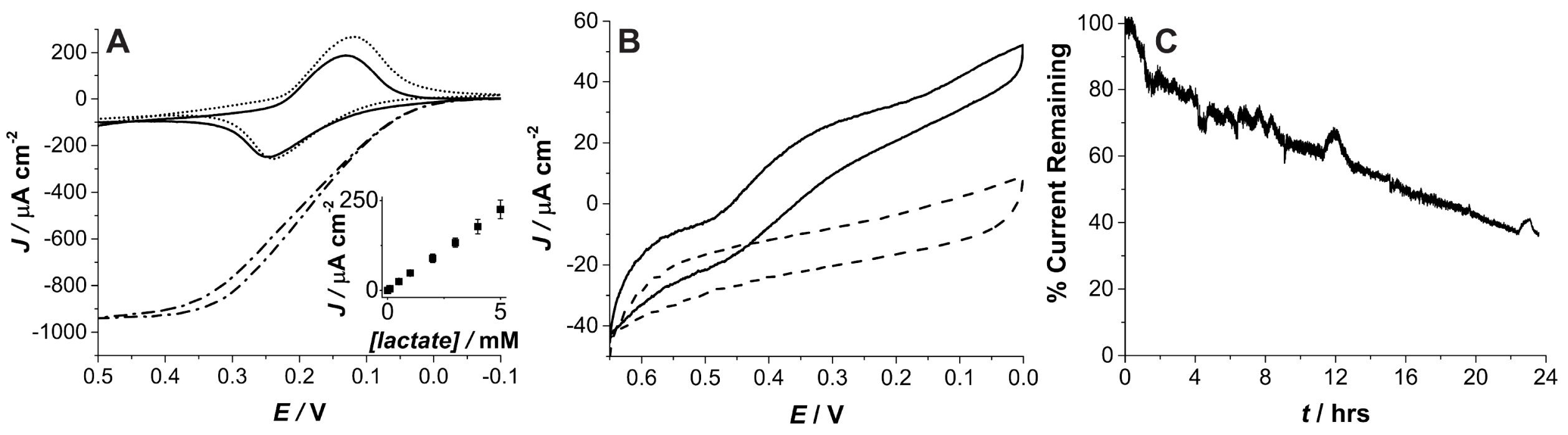


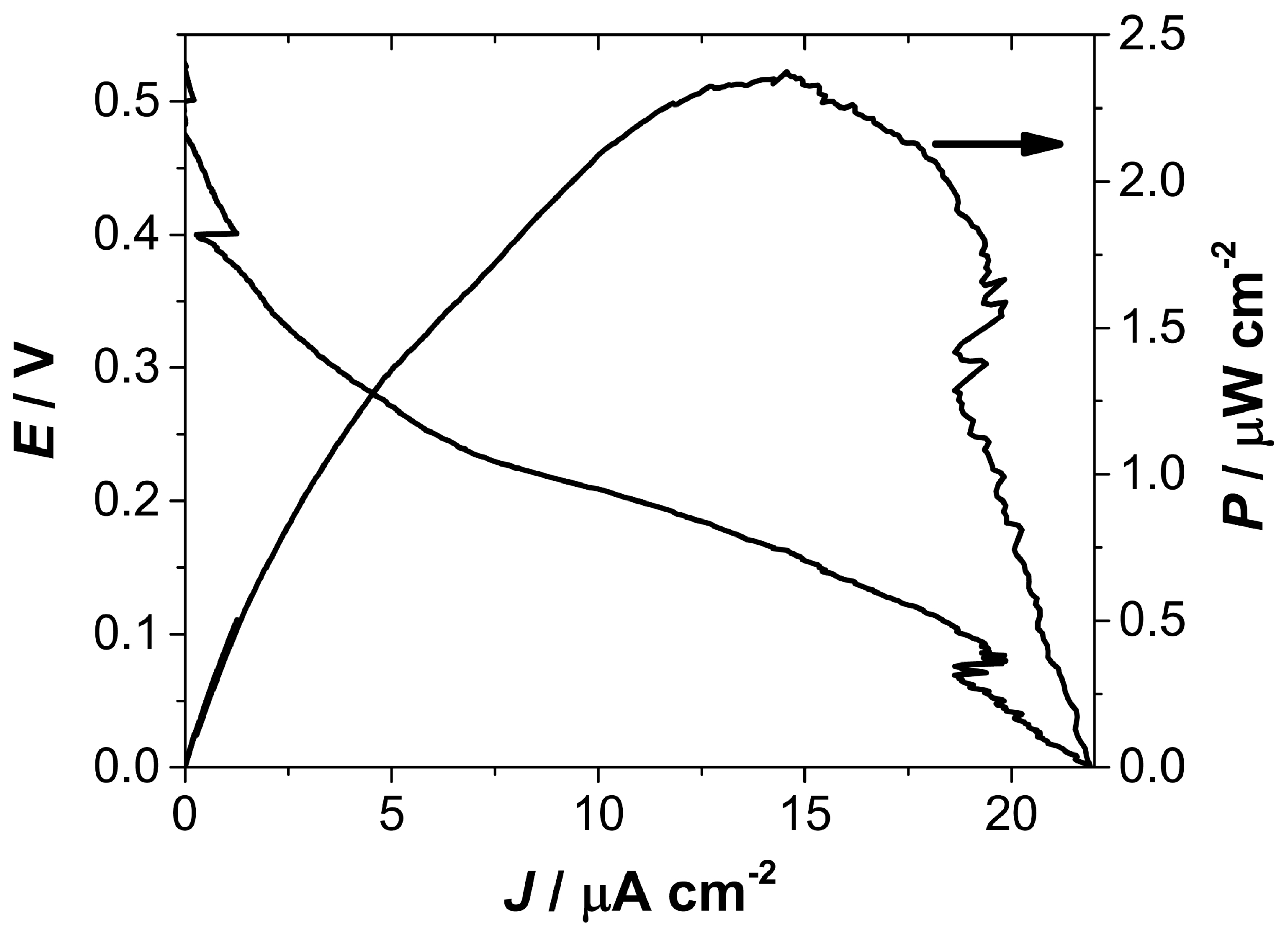




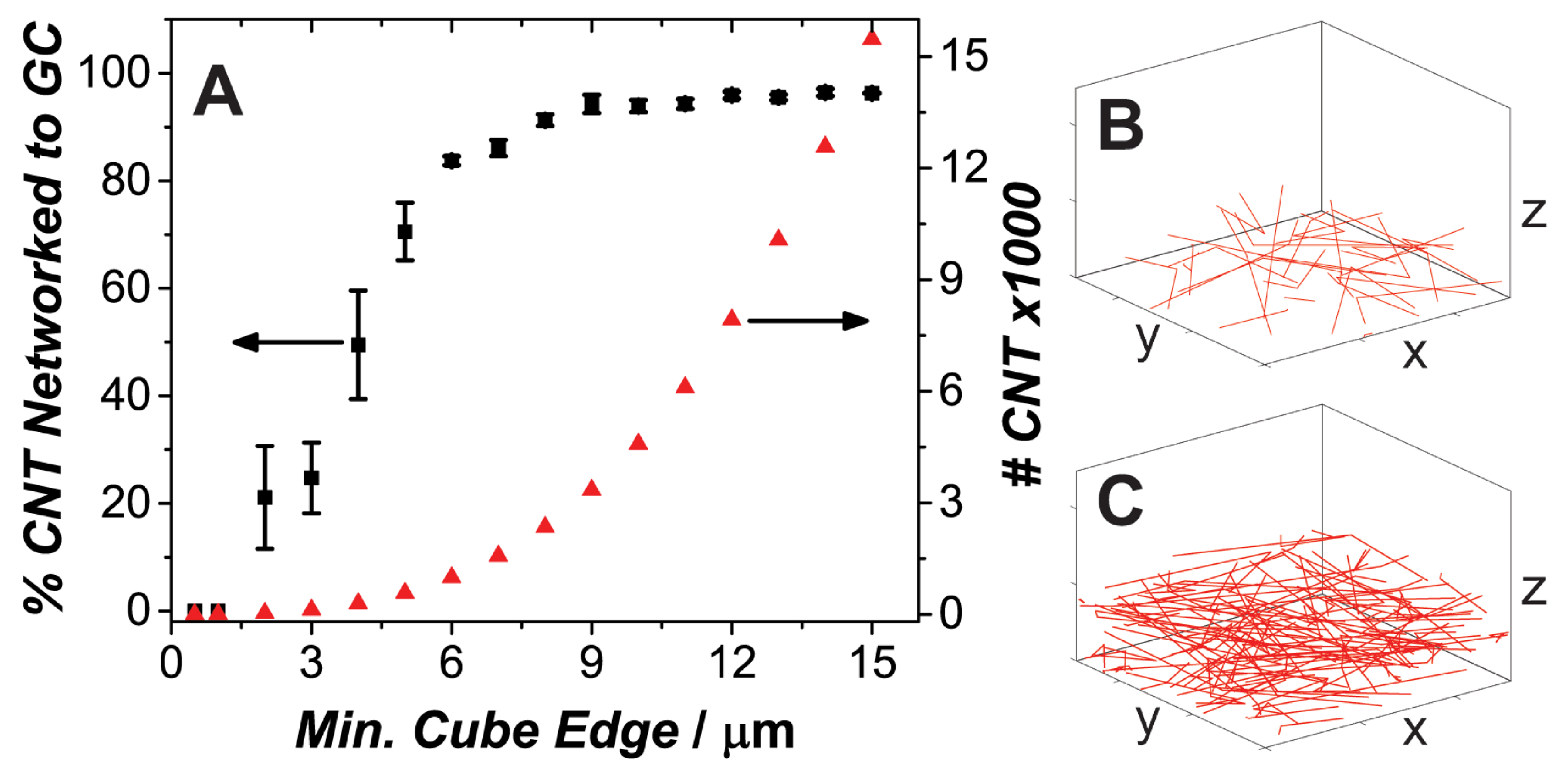



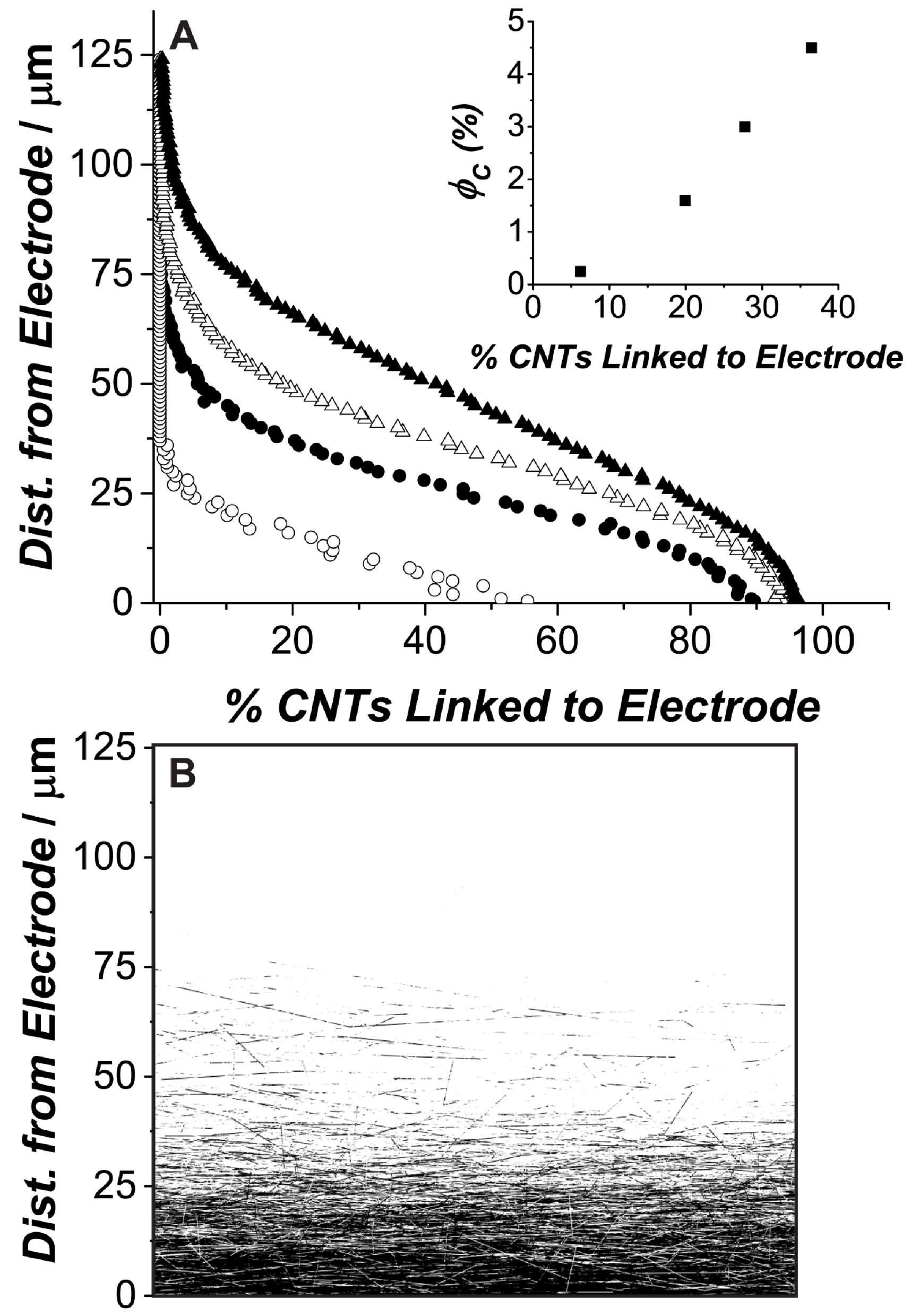

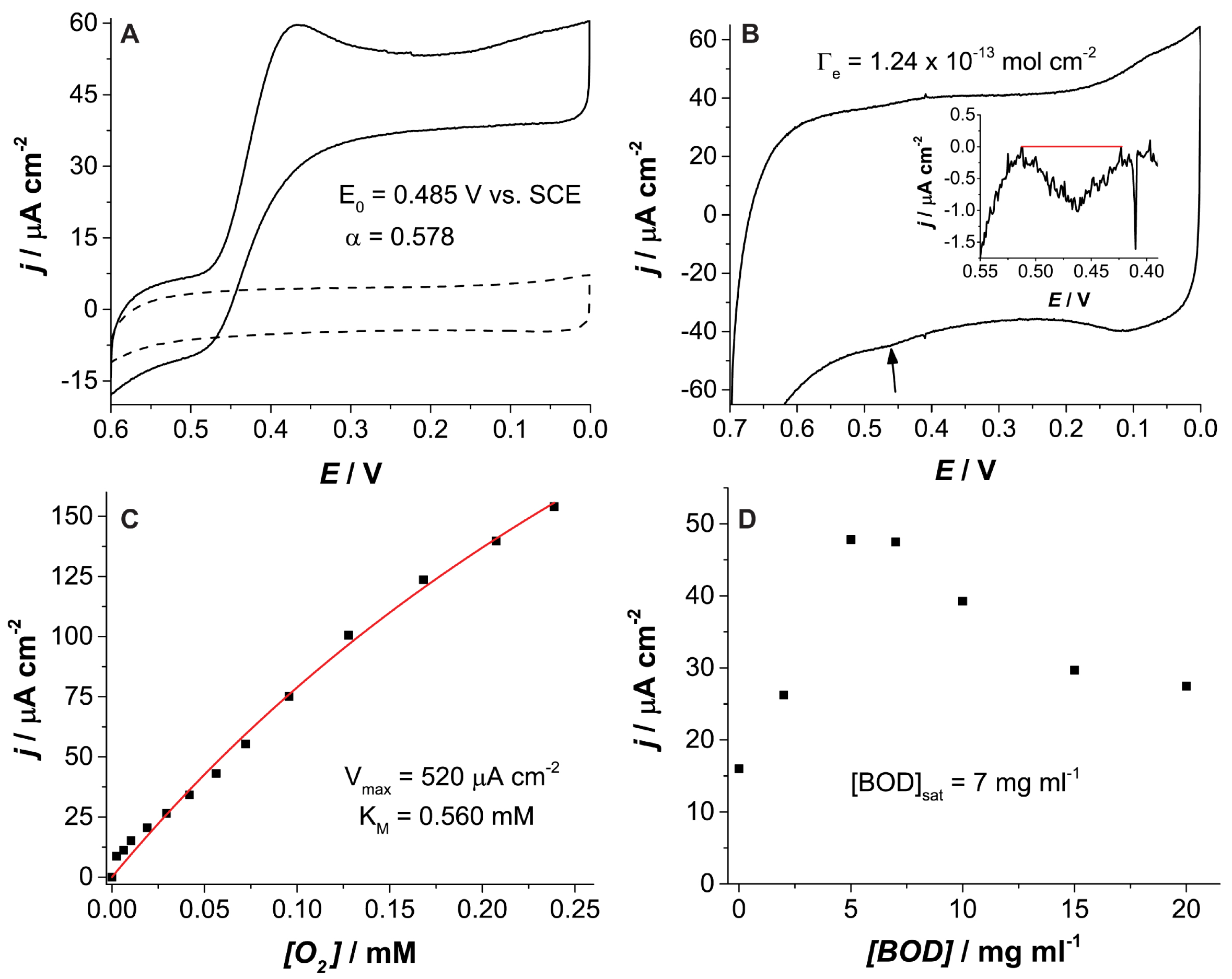


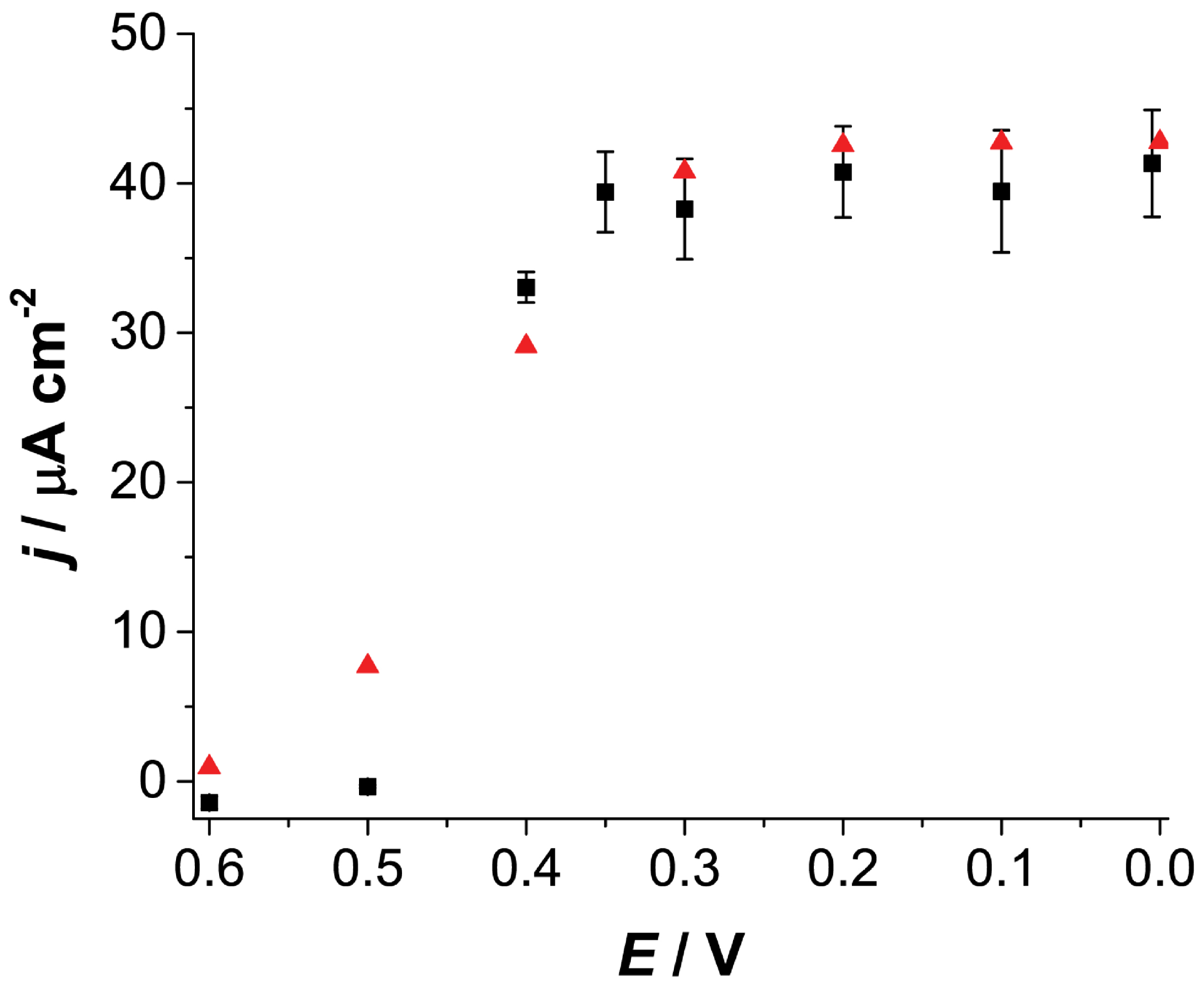


Table 1. Parameters used in the CNT connectivity and cathode current density models

\begin{tabular}{|c|c|c|c|}
\hline Parameter & Value & Description & Source \\
\hline$t_{\text {film }}$ & $125 \mu \mathrm{m}$ & $\begin{array}{l}\text { CNT-filled TBAB-modified Nafion } \\
\text { hydrated film thickness }\end{array}$ & Measured \\
\hline$\phi_{\mathrm{C}}$ & $1.6 \%$ & Vol. \% of CNT in film & Calculated \\
\hline$D$ & $25 \mathrm{~nm}$ & CNT diameter & Supplier datasheet \\
\hline $\boldsymbol{L}$ & $20 \mu \mathrm{m}$ & CNT length & Supplier datasheet \\
\hline$d_{e}$ & $1.8 \mathrm{~nm}$ & Electron hopping distance & [56] \\
\hline$l_{x}=l_{y}$ & $13 \mu \mathrm{m}$ & $\begin{array}{l}\text { Simulated film side length in } \mathrm{x} \text { - } \\
\text { and } \mathrm{y} \text {-directions }\end{array}$ & Figure 7A \\
\hline$l_{z}$ & $125 \mu \mathrm{m}$ & $\begin{array}{l}\text { Simulated film side length in z- } \\
\text { direction }\end{array}$ & Same as $t_{\text {film }}$ \\
\hline$(x, y, z)$ & random & CNT vertex $\in\left[0,\left(l_{x}, l_{y}, l_{z}\right)\right]$ & $\begin{array}{c}\text { MATLAB } \\
\text { random number generator }\end{array}$ \\
\hline $\begin{array}{l}\alpha_{\mathbf{1}}\left(\in\left[\mathbf{0}, \mathbf{1 8 0}^{\circ}\right]\right), \\
\theta_{1}\left(\in\left[\mathbf{0}, \mathbf{3 6 0}^{\circ}\right]\right)\end{array}$ & random & $\begin{array}{c}\text { Orientation angles of one CNT } \\
\text { branch }\end{array}$ & $\begin{array}{l}\text { MATLAB } \\
\text { random number generator }\end{array}$ \\
\hline $\begin{array}{l}\boldsymbol{\alpha}_{2}\left(\in\left[\mathbf{0}, \mathbf{1 8 0}^{\circ}\right]\right) \\
\boldsymbol{\theta}_{2}\left(\in\left[\mathbf{0}, \mathbf{3 6 0}^{\circ}\right]\right)\end{array}$ & random & $\begin{array}{l}\text { Orientation angles of the other } \\
\text { CNT branch }\end{array}$ & $\begin{array}{c}\text { MATLAB } \\
\text { random number generator }\end{array}$ \\
\hline$\gamma\left(\in\left[\mathbf{0}, \mathbf{1 8 0}^{\circ}\right]\right)$ & random & Angle between CNT branches & $\begin{array}{l}\text { Dependent on CNT branch } \\
\text { orientation angles and } L\end{array}$ \\
\hline$D_{O_{2}}$ & $\begin{array}{l}1.048 \times 10^{-11} \\
\mathrm{~m}^{2} \mathrm{~s}^{-1}\end{array}$ & $\mathrm{O}_{2}$ diffusion through Nafion & {$[75]$} \\
\hline$\left[\mathrm{O}_{2}\right]_{\mathrm{H}_{2} \mathbf{0} \text {,air sat. }}$ & $0.26 \mathrm{~mol} \mathrm{~m}^{-3}$ & Dissolved $\mathrm{O}_{2}$ concentration & [76] \\
\hline$K_{M}$ & $0.560 \mathrm{~mol} \mathrm{~m}^{-3}$ & Michaelis constant & Measured \\
\hline $\boldsymbol{k}_{\text {cat }}$ & $200 \mathrm{~s}^{-1}$ & Turnover number & [39] \\
\hline$k_{0}$ & $\begin{array}{c}75 \mathrm{~m}^{3} \\
(\mathrm{~mol} \cdot \mathrm{s})^{-1}\end{array}$ & Heterogeneous rate constant & $\begin{array}{l}\text { Fit to cyclic voltammogram } \\
\text { data }\end{array}$ \\
\hline$\alpha$ & 0.578 & Transfer coefficient & Measured \\
\hline$E$ & $\begin{array}{l}\text { Independent } \\
\text { variable }\end{array}$ & Applied voltage & $\begin{array}{l}\text { Varied from } 0.6 \text { to } 0 \mathrm{~V} \text { vs. } \\
\text { SCE }\end{array}$ \\
\hline$E_{0}$ & $\begin{array}{c}0.485 \mathrm{~V} \\
\text { (vs. SCE) }\end{array}$ & $\mathrm{O}_{2}$ reduction onset potential & Measured \\
\hline $\boldsymbol{n}_{e, \mathbf{0}_{2}}$ & 4 & e transferred in $\mathrm{O}_{2}$ reduction & [46] \\
\hline$n_{e, \mathrm{BOD}}$ & 1 & $\mathrm{e}^{-}$transferred in BOD oxidation & {$[77,78]$} \\
\hline$n_{C N T}$ & $1.4551 \times 10^{9}$ & Number of CNTs in film & Calculated \\
\hline$f_{\text {conn }}$ & 0.199 & $\begin{array}{l}\text { Fraction of CNTs connected to } \\
\text { GC electrode }\end{array}$ & MATLAB connectivity model \\
\hline$\Gamma_{e}$ & $\begin{array}{l}4.95 \times 10^{-13} \\
\mathrm{~mol} \mathrm{~cm}^{-2}\end{array}$ & BOD surface concentration & Measured \\
\hline$Q$ & $3.14 \times 10^{-7} \mathrm{C}$ & Charge transfer from BOD & Measured \\
\hline$A$ & $6.58 \mathrm{~cm}^{2}$ & $\begin{array}{l}\text { Total CNT surface area } \\
\text { networked to electrode }\end{array}$ & MATLAB connectivity model \\
\hline$f_{\text {active }}$ & $\begin{array}{c}\text { Fitting } \\
\text { parameter }\end{array}$ & $\begin{array}{l}\text { Electrochemically active fraction } \\
\text { of CNT surface }\end{array}$ & -- \\
\hline
\end{tabular}




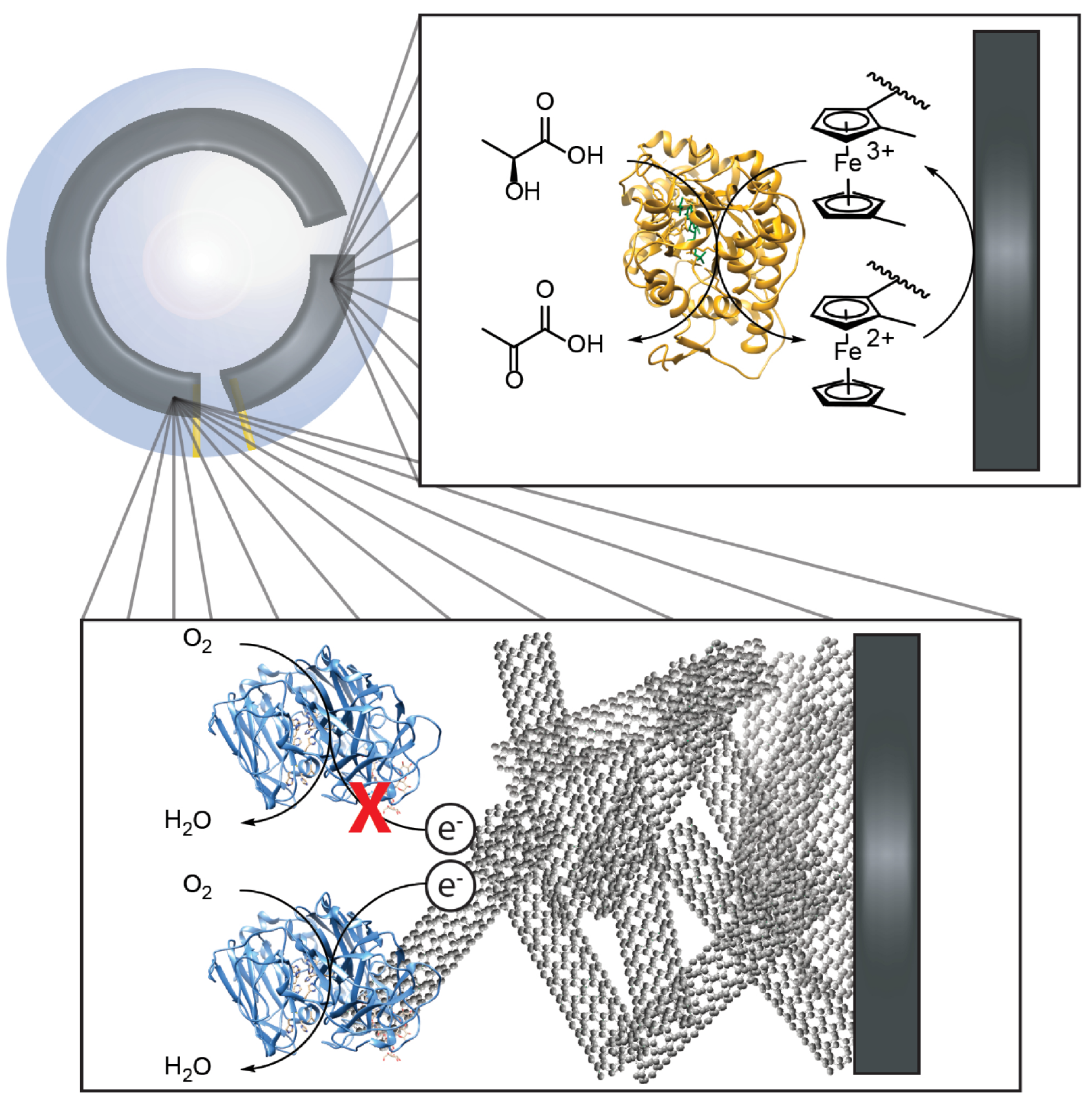

